\title{
The TFOS International Workshop on Contact Lens Discomfort: Report of the Contact Lens Interactions With the Ocular Surface and Adnexa Subcommittee
}

\author{
Nathan Efron, ${ }^{1}$ Lyndon Jones, ${ }^{2}$ Anthony J. Bron, ${ }^{3}$ Erich Knop, ${ }^{4}$ Reiko Arita, ${ }^{5}$ Stefano Barabino, ${ }^{6}$ \\ Alison M. McDermott, ${ }^{7}$ Edoardo Villani, ${ }^{8}$ Mark D. P. Willcox, ${ }^{9}$ Maria Markoulli, ${ }^{9}$ and the members \\ of the TFOS International Workshop on Contact Lens Discomfort
}

\footnotetext{
${ }^{1}$ Institute of Health and Biomedical Innovation, and School of Optometry and Vision Science, Queensland University of Technology, Kelvin Grove, Queensland, Australia

${ }^{2}$ Centre for Contact Lens Research, School of Optometry and Vision Science, University of Waterloo, Waterloo, Ontario, Canada ${ }^{3}$ Nuffield Laboratory of Ophthalmology, University of Oxford, Oxford, United Kingdom

${ }^{4}$ Ocular Surface Center Berlin, Department for Cell and Neurobiology, Center for Anatomy, Charité-Universitätsmedizin Berlin, Berlin, Germany

${ }^{5}$ Itoh Clinic, Saitama, Japan

${ }^{6}$ Clinica Oculistica, Dipartimento di Neuroscienze, Riabilitazione, Oftalmologia, Genetica, e Scienze Materno Infantili, University of Genoa, Genoa, Italy

${ }^{7}$ The Ocular Surface Institute, University of Houston College of Optometry, Houston, Texas

${ }^{8}$ Department of Clinical Sciences and Community Health, University of Milan and Eye Clinic San Giuseppe Hospital, Eye Clinic Fondazione IRCCS Ca' Granda Ospedale Maggiore Policlinico, Milan, Italy

${ }^{9}$ School of Optometry and Vision Science, The University of New South Wales, Sydney, New South Wales, Australia
}

Correspondence: Lyndon Jones; 1wjones@uwaterloo.ca.

See the tables in the Introduction for the members of the TFOS International Workshop on Contact Lens Discomfort.

Submitted: September 3, 2013

Accepted: September 4, 2013

Citation: Efron N, Jones L, Bron AJ, et al. The TFOS International Workshop on Contact Lens Discomfort: Report of the Contact Lens Interactions With the Ocular Surface and Adnexa Subcommittee. Invest Ophthalmol Vis Sci. 2013;54:TFOS98-TFOS122. DOI:10.1167/iovs.13-13187

Keywords: contact lenses, discomfort, dryness, cornea, conjunctiva, eyelids

$\mathrm{T}$ he report of this subcommittee concerns the impact of contact lenses (CLs) on the ocular surface, with a particular emphasis on CL discomfort (CLD). We define the ocular surface, its regional anatomy, and the physiological responses of each region to CL wear.

\section{Definition of the Ocular Surface}

The ocular surface consists of the continuous mucosal surface that begins with the cornea centrally and extends, via the limbus, to the bulbar and fornical conjunctiva to end with the tarsal conjunctiva. ${ }^{1,2}$ Classically, the tarsal conjunctiva is further subdivided into proximal and distal parts by the presence of a subtarsal fold, ${ }^{3}$ which runs parallel to the lid margin at approximately $2 \mathrm{~mm}$ from its posterior border. The distal part, termed the marginal conjunctiva, is of particular importance to lid function during blinking and extends from the fold to the mucocutaneous junction on the occlusal surface of the lid margin. That part that is apposed to the globe is the site of the so-called "lid wiper" zone of the lid, which has an important role in distributing the tear film across the ocular surface. Many aspects of the ocular surface are covered in several excellent reviews, including the functional anatomy and immunology, ${ }^{4-6}$ ocular allergy, ${ }^{7,8}$ and ocular surface reconstruction. ${ }^{9-15}$

Copyright 2013 The Association for Research in Vision and Ophthalmology, Inc. www.iovs.org | ISSN: 1552-5783

\section{The Tears and Tear Film}

The exposed ocular surface is at all times covered by the tear film. When the eyes are closed, the tear-filled space so formed is termed the conjunctival sac. Aqueous tears, secreted by the main and accessory lacrimal glands, enter the upper and outer parts of the sac, replenishing the tears. As the eyes open, in the upstroke of the blink, the tears exposed by the widening palpebral fissure form the preocular tear film and the tear menisci. ${ }^{16-18}$ The precorneal tear film is estimated to be approximately $3 \mu \mathrm{m}$ in thickness. ${ }^{19}$

The menisci, lying at the interface between the lid margins and the surface of the globe, provide the route by which the tears reach the lacrimal puncta and canaliculi and thence enter the nasolacrimal system. In the steady state, tears lost from the exposed ocular surface by evaporation during the blink interval and those lost by tear drainage, balance that produced by tear secretion. Meibomian lipid (meibum), derived from the tarsal meibomian glands, is delivered to the lid margin skin just anterior to the mucocutaneous junction and is spread onto the surface of the tear film in the upstroke of the blink. ${ }^{20,21}$ The tear film lipid layer retards evaporative water loss from the eye, playing a critical role in protecting the ocular surface from desiccating stress. 


\section{Integrated Lacrimal Functional Unit}

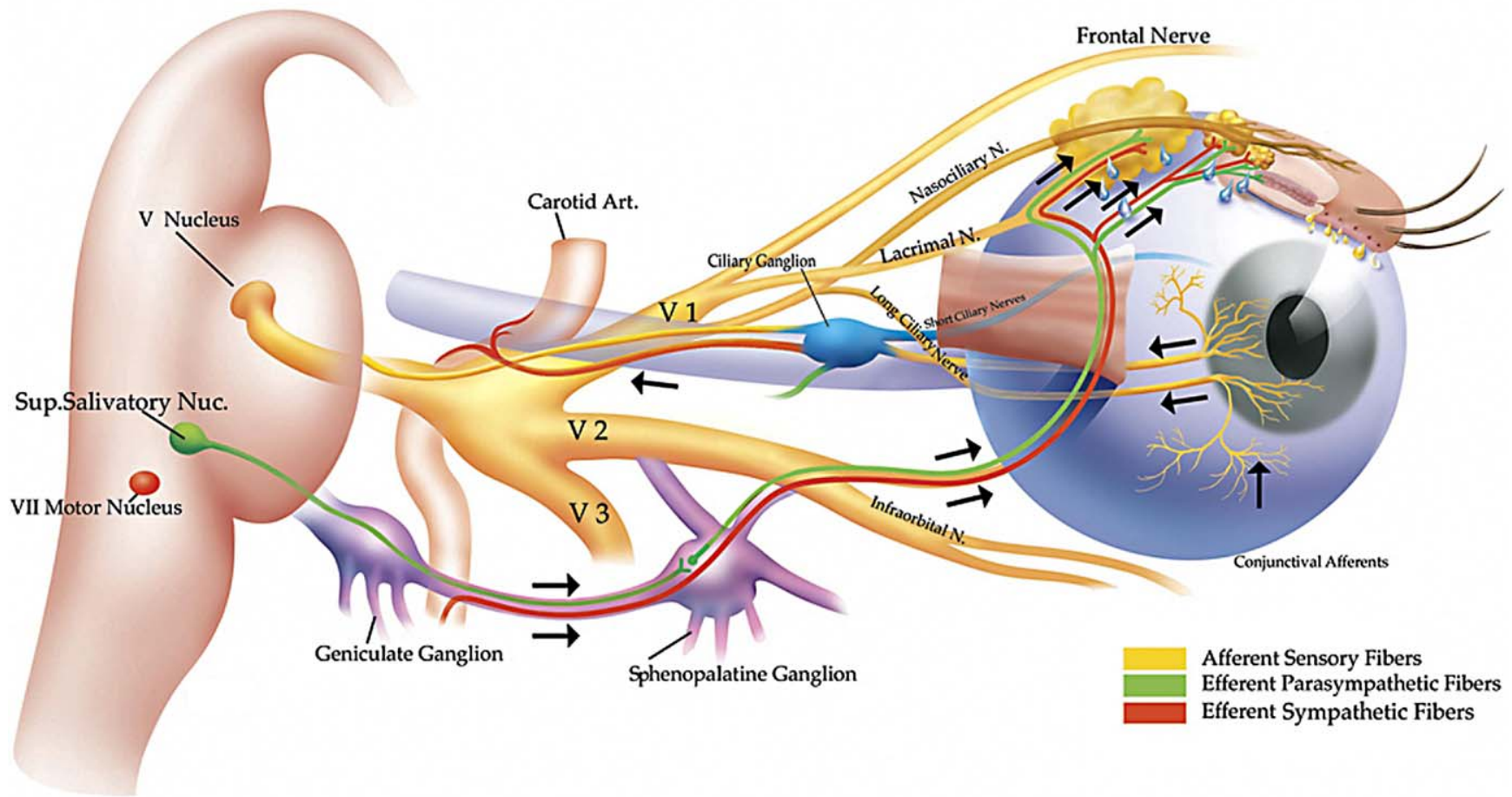

FiguRE 1. The Lacrimal Functional Unit is an integrated system comprising the lacrimal glands, ocular surface (cornea, conjunctiva, meibomian glands, goblet cells, and lids), and the sensory and motor nerves that connect them. Trigeminal sensory fibers arising from the ocular surface, particularly the cornea, run to the superior salivary nucleus in the pons, from where efferent fibers pass, in the nervus intermedius, to the sphenopalatine ganglion. Here, postganglionic fibers arise that terminate in the lacrimal gland, nasopharynx, and vessels of the orbit. Another neural pathway controls the blink reflex, via trigeminal afferents and the somatic efferent fibers of the seventh cranial nerve. Higher centers feed into the brainstem nuclei and there is a rich sympathetic supply to the epithelia and vasculature of the glands and ocular surface. ${ }^{23}$ Figure courtesy of Michael Stern.

\section{Ocular Surface AND the Lacrimal-FunCtional UNIT}

The ocular surface may be thought of as an integrated functional unit, ${ }^{5,22,23}$ protected from environmental stress by homeostatic processes that control tear flow and tear film formation. ${ }^{24}$ In addition to the cornea and conjunctiva, ${ }^{4}$ its component parts include the main ${ }^{25-27}$ and accessory lacrimal glands, ${ }^{28}$ the meibomian glands ${ }^{29}$ and mucin-producing epithelial cells and goblet cells, ${ }^{30}$ the blink mechanism, ${ }^{31}$ and events accompanying the closed eye condition. ${ }^{32}$ Homeostasis involves, in particular, a reflex arc between the ocular surface and the brain stem, ${ }^{33,34}$ and in addition, immunologic, ${ }^{35}$ inflammatory, ${ }^{35}$ and endocrine regulation. ${ }^{36}$

The ocular surface is richly innervated by trigeminal afferents and the lacrimal and meibomian glands each receive a parasympathetic and a sympathetic nerve supply. Inputs and outputs from these nerves form the basis of a reflex arc between the ocular surface, brainstem, and lacrimal glands, which adjusts tear secretion to meet daily demands. This is referred to as the lacrimal functional unit. ${ }^{33,34,37}$ The sensory innervation of the cornea is particularly rich, ${ }^{38}$ while that of the lid margin mucosa is similar to that of the central cornea. ${ }^{39}$ These afferents cooperate to stimulate reflex tear production and spontaneous blinking, in addition to mediating sensation. Additional inputs to the lacrimal gland from higher centers of the brain are involved in emotional tears. Sensory inputs from the nasolacrimal system may suppress tear production. ${ }^{40}$ Figure 1 graphically portrays this integrated system.
A loss of sensory drive to the brain stem salivary or blink centers can inhibit tear secretion ${ }^{41-44}$ and reduce the rate of spontaneous blinking, ${ }^{45,46}$ compounding the effect of desiccating stresses to the eye. Impairment of feedback by either injury or inflammatory cytokines acting on the ocular surface may be an important contributor to ocular surface inflammation in dry eye disease. . $^{4,33,34,47-54}$

\section{Interactions With the Ocular Surface}

Contact lens discomfort must relate to the interactions between the CL and the ocular surface and alterations to its tissues during lens wear. These changes are described below on a regional basis.

\section{IMPACT OF CLS ON THE CORNEA}

\section{Corneal Structure and Function}

The cornea is the transparent, anterior, avascular part of the corneoscleral envelope, separated from the sclera by the limbus. It has a rich sensory nerve supply from the trigeminal nerve, ${ }^{55,56}$ details of which are discussed in the subcommittee report on the neurobiology of discomfort and pain.

The cornea is covered by a stratified squamous, nonkeratinized epithelium whose surface cells are connected by tight junctions that seal the intercellular space. These cells exhibit microplicae, which increase the surface area and facilitate interactions with the tear film. The apical membranes of these 
cells express a glycocalyx composed chiefly of transmembrane mucins, ${ }^{30}$ which confers wettability to the corneal surface. ${ }^{57} \mathrm{~A}$ similar arrangement occurs in the conjunctiva. The glycocalyx, together with the tight junctions, creates a relatively impervious barrier to the passage of small, water-soluble molecules, such as the dyes used in clinical practice to stain the cornea (e.g., fluorescein and lissamine green). ${ }^{58,59}$ This is the basis for the very limited degree of punctate staining of the cornea and conjunctiva seen in the normal eye.

Deeper cells are highly interdigitated and connected by desmosomes. The deepest layer consists of columnar, basal cells, which are approximately $10 \mu \mathrm{m}$ in diameter. The intercellular space, narrow in the normal epithelium, is expanded in the presence of epithelial edema and the separation of these regularly arranged cells, acting as a diffraction grating, is responsible for the "rainbows around lights" reported in the presence of early epithelial edema. ${ }^{60}$ Specialized adhesion complexes, consisting of hemidesmosomes, anchoring fibrils, and anchoring plaques attach these cells firmly to the underlying anterior limiting layer, which is composed of fine, tightly woven collagen fibrils. ${ }^{61}$ These form a smooth, rigid base for the epithelium.

The transparent stroma is one of the most highly organized tissues of the body, composed of collagen fibrils arranged as flat lamellae, lying within a matrix of proteoglycans. The lamellae show greater interweave anteriorly, where a proportion are inserted into Bowman's layer. ${ }^{62,63}$ The narrow and highly uniform width and spacing of the fibrils within the lamellae is the basis of stromal transparency. ${ }^{64}$ Peripherally, as the lamellae pass through the limbus to combine with the sclera, this order is lost and the marked variation in fibril diameter and spacing results in the opacity of the sclera. Sandwiched between the lamellae are the keratocytes, which form an interconnecting network coupled by gap junctions. ${ }^{65,66}$ These cells are responsible for production and maintenance of the stromal collagen and the proteoglycans, which maintain spacing between the collagen fibrils. Keratocytes, transforming to myofibroblasts, are also the source of the fibrotic response to corneal stromal injury, ${ }^{67,68}$ which can lead to permanent scarring.

Descemet's membrane is the basal lamina of the endothelium and forms a scaffold over which endothelial cells may spread to maintain continuity following cell loss or injury. Contiguous cells are joined by macula occludens junctions, which form a more leaky barrier than that found in the epithelium. They permit the movement of water and nutrients from the aqueous humor into the cornea. The energydependent activity of the corneal endothelium, driving $\mathrm{Na}^{+} /$ $\mathrm{K}^{+}$-activated ion pumps, and the movement of sodium $\left(\mathrm{Na}^{+}\right)$ and bicarbonate $\left(\mathrm{HCO}_{3}{ }^{-}\right)$ions out of the cornea, leads to a steady, osmotically driven, outward movement of water into the anterior chamber. ${ }^{69}$ This generates a negative hydrostatic pressure within the stroma, reduces its water content (corneal deturgescence), and preserves the regular order of the collagen fibrils necessary for its transparency. This negative pressure, transmitted to the intercellular spaces of the epithelium, ensures that it is normally edema-free.

When endothelial function fails and the hydrostatic pressure in the stroma becomes less negative, the stroma swells, fibril order is lost, and the cornea thickens and becomes progressively less transparent. Stromal swelling is more limited anteriorly where the lamellar interweave is greatest. ${ }^{70,71}$ In the presence of a normal ocular pressure, when the hydrostatic pressure becomes positive, epithelial corneal edema also occurs $^{72,73}$ and there is a further and more marked loss of transparency, due to irregular, surface astigmatism. Epithelial, and to some extent stromal edema, may also result from breaches in the corneal epithelium.
In humans, mature corneal endothelial cells do not divide significantly and their density decreases with age, ${ }^{74}$ and cells spread and enlarge to maintain a functional monolayer. Excessive cell loss due to injury can disturb the functional integrity of the endothelium, leading to corneal decompensation, stromal swelling, and loss of transparency. ${ }^{75}$

The nutrition of the cornea relies almost entirely on materials supplied by the aqueous humor. The oxygen supply is provided by the tear film for the anterior cornea and from the anterior chamber for the posterior cornea. Carbon dioxide, the product of cellular metabolism, is readily lost to the atmosphere.

\section{Epithelium}

Many different effects of CL wear on the corneal epithelium have been reported. The epithelial cells of the cornea secrete a range of active soluble molecules into the tear film. This is discussed more fully in the subcommittee report on the CL interactions with the tear film.

Morphological Changes. CL wear has a number of effects on corneal morphology and ultrastructure, including epithelial thinning and increased cell size. ${ }^{76-78}$ Using specular microscopy, Mathers and colleagues ${ }^{79}$ reported that extended wear (EW) soft contact lenses (SCL) and daily wear (DW) rigid lenses resulted in larger epithelial cells than controls, whereas the epithelial cells of DW SCL subjects were not different from controls. Similarly, other studies show that while mean cell area is not affected by DW, lenses worn on an EW modality induce a gradual increase in cell area. ${ }^{80-84}$

Epithelial cells harvested by corneal impression cytology from SCL wearers were also found to be larger than those from non-lens wearers. ${ }^{85,86}$ Overall, for hydrogel and silicone hydrogel (SiHy) DW lenses, effects on cell size are minor but become more obvious with EW. ${ }^{77}$ For rigid lenses, cells increase in size by $10 \%$ to $30 \%$ during DW. ${ }^{87}$ One hypothesis for this increase in cell size is that it is associated with slowing of epithelial renewal, such that cells are retained on the surface for a longer period of time, allowing more time for them to flatten and enlarge, ${ }^{84}$ but other factors, such as mechanical compression, particularly with rigid lenses, may be involved. ${ }^{77}$ Holden and colleagues ${ }^{88}$ reported that long-term EW of SCL caused a $5.6 \%$ decrease in epithelial thickness. Several other studies have used in vivo laser scanning confocal microscopy (LSCM) to study lens effects on the epithelium. Ladage and colleagues $^{87}$ did not see an effect on epithelial thickness after 4 weeks of DW SCL, whereas an almost 10\% decrease in thickness was observed with rigid lens wear. They also noted that epithelial cell surface area increased 3\% to 10\%, depending on lens type. Patel and colleagues ${ }^{89}$ showed that temporal but not central epithelial thickness was reduced in corneas of longterm ( $>10$ years) CL wearers. Corneal epithelial basal cells were found to be less regular in low oxygen transmissibility $(\mathrm{Dk} / \mathrm{t})$ lens wearers than high Dk/t and non-lens wearers, and both types of lens wear were associated with epithelial thinning, compared with non-lens wearers. ${ }^{90}$ Yagmur and colleagues $^{91}$ studied the eyes of hydrogel CL wearers (average wear duration of approximately 3.5 years) and controls. They observed that corneal epithelial cells were enlarged in eyes wearing lenses with a mean Dk/t ratio of approximately 27 . They attributed this and other corneal changes, such as reduced keratocyte density, to both mechanical and hypoxic effects. A recent review by Robertson ${ }^{76}$ summarizes epithelial thickness and size changes with various materials as a function of wear modality and the author suggests partial dependence on oxygen transmission for thinning associated with overnight hydrogel wear, but a mechanical cause for that seen with firstgeneration SiHy lenses. 
Alonso-Caneiro and colleagues ${ }^{92}$ recently reported on the use of optical coherence tomography to assess the effects of 6 hours of SCL wear on morphology. Subtle, but significant, changes were observed and these were most apparent at the limbus, presumably due to greater pressure in this area. Epithelial thinning of $2.84 \pm 0.84 \mu \mathrm{m}$ was observed for the cornea versus $5.47 \pm 1.71 \mu \mathrm{m}$ for the limbus, with the SiHy lens causing the least surface changes.

A scanning electron microscopic study on samples of epithelium harvested prior to photorefractive keratectomy showed that there was no difference in the number of surface microvilli among CL wearers and non-lens wearers, but that epithelial mucin was reduced in the lens-wearing group. ${ }^{93}$ Morphological studies in orthokeratology models have revealed an expected central epithelial thinning and peripheral thickening for myopic correction, and the reverse for hyperopic corrections. ${ }^{94-97}$ Nieto-Bona and colleagues ${ }^{97}$ used LSCM to study epithelial morphological changes induced by 1 month use of orthokeratology lenses. Basal epithelial cell density was reduced and wing and superficial cells showed enhanced visibility. Superficial cells also were increased in height and width.

To date, no direct correlation between any of these morphological changes with CLD has been reported.

Epithelial Homeostasis. Studies have shown that the normal process of sloughing of corneal epithelial cells is impeded by CL wear. This occurs with all lens types and wear modalities and tends to recover over time, suggesting that an adaptation to lens wear occurs. ${ }^{87,98,99}$ Normal exfoliation is an apoptotic process driven by factors such as eyelid shear forces and centripetal pressure and involves loss of superficial cell expression of the antiapoptotic protein $\mathrm{Bcl}-2$ prior to sloughing. Yamamoto and colleagues ${ }^{100}$ observed a reduction in the total number of Bcl-2-negative and TUNEL- (marker for apoptosis) staining cells, suggesting that rigid lens wear blocks necessary changes in $\mathrm{Bcl}-2$ expression that must occur before exfoliation is possible. Lens-induced effects on desquamation do not appear to be related to lens $\mathrm{Dk} / \mathrm{t} \cdot{ }^{77,101}$

More than a decade of studies indicate that lens wear inhibits basal epithelial cell proliferation in the central cornea, causes delay in vertical migration as cells move toward the surface, and reduces apoptotic desquamation of superficial cells. As normal corneal epithelial homeostasis helps maintain a smooth surface for refraction of light and barrier function, compromise to this process could contribute to ocular surface changes that lead to CLD. However, to date, no direct correlation has been demonstrated.

Barrier Function. The corneal epithelium forms a formidable barrier to the external environment and disruption of the barrier may result in edema and permit entry of microbes. Thus, compromise of the barrier by CL wear is an important issue. Although an early study by Boets and colleagues $^{102}$ did not show any difference in corneal epithelial permeability in CL wear using a peroxide or biguanide care solution, hypoxia associated with lens wear has been implicated in reducing corneal barrier function.

Clinical studies using fluorometry to quantify fluorescein penetration from the tear film to the stroma, indicate that hypoxia and also tear stagnation play a significant role in reducing epithelial barrier function with various modalities of lens wear. ${ }^{103-107}$ However, other factors are also involved. Two studies using SiHy lenses, which eliminate concerns associated with hypoxia, confirm this. Lin and colleagues ${ }^{108}$ demonstrated changes in epithelial permeability under a 30-day continuous wear modality. Notably, Asian eyes appeared to be more susceptible to permeability changes than non-Asian eyes. Duench and colleagues ${ }^{109}$ demonstrated an increase in epithelial permeability with DW of a SiHy lens, which they proposed was due to mechanical effects from the stiffer SiHy material. They were also able to show increases associated with the use of solutions. No direct link between CLD and epithelial permeability has been shown.

Corneal Erosions. CL wear has been associated with corneal erosions, in which a full-thickness detachment of epithelium in a localized, well-circumscribed area of the cornea occurs. ${ }^{110-112}$ As reviewed by Markoulli and colleagues, ${ }^{111}$ several mechanisms may be involved, including lens adhesion, mechanical damage from exacerbated thinning due to lens dehydration, bacterial proteases, and reduced epithelial density leading to reduced hemidesmosomes. Hypoxia-related decreased carbon dioxide efflux and epithelial cell acidification may contribute to altered cell appearance and metabolism during wearing of lenses with low Dk/t. ${ }^{113,114}$ This complication is typically symptomatic, especially following lens removal.

Corneal Staining. "Corneal staining" is a general term that refers usually, to the punctate uptake of a dye, such as fluorescein, rose Bengal, or lissamine green, into the corneal epithelium. ${ }^{115}$

Corneal staining is an ubiquitous feature of CL wear; however, it is important to note that it is also frequently observed in non-lens wearers. ${ }^{116,117}$ The frequency of corneal staining of any severity in a population of CL wearers may be as high as $60 \%,{ }^{116}$ but often staining is of a low level and generally clinically insignificant. Brautaset and colleagues ${ }^{118}$ reported an incidence of $19.5 \%$ corneal staining among 338 adapted hydrogel lens wearers, with no subjects displaying staining greater than grade 2 (on a $0-4$ scale).

Corneal staining can be caused by a number of factors, which can be grouped into various categories, including mechanical, inflammatory, exposure, metabolic, toxic, allergic, and infectious. Sources of mechanical staining include lens defects, poor lens quality (e.g., rough edge), ${ }^{119}$ lens binding (which may occur with overnight EW rigid lenses), ${ }^{120}$ excessive lens bearing due to poor fit, foreign bodies beneath the lens, or abrasion occurring during lens insertion or removal.

In SCL wearers, exposure keratitis manifests typically as a band of inferior arcuate staining. ${ }^{121,122}$ This is due to epithelial disruption as a result of drying of the corneal surface ${ }^{121-123}$ and is often associated with incomplete blinking. Desiccation staining with SCL can be categorized as a form of exposure keratitis. ${ }^{124,125}$ This condition appears as a central punctate stain and most often occurs when high water content lenses are made too thin, causing water to be drawn out of the cornea when the lens dehydrates. ${ }^{126}$ The classic pattern of 3 and 9 o'clock staining in rigid lens wearers is also primarily thought to represent a form of exposure keratitis, whereby the eyelids are bridged away from the corneal surface at the lens edge at the 3 and 9 o'clock corneal locations. ${ }^{127}$

All CLs are known to induce various levels of epithelial hypoxia and hypercapnia, ${ }^{128}$ resulting in the production of various metabolites (e.g., lactic and carbonic acid). Evidence that such changes can adversely affect comfort is lacking.

In a case-control study of 413 CL wearers, Nichols and Sinnott ${ }^{129}$ examined a variety of lens- and subject-related factors, to determine their potential association with sodium fluorescein corneal staining. Several factors were shown to be related to increased corneal staining, including increased daily wearing times $(P=0.0006)$, lower income $(P=0.0008)$, lissamine green conjunctival staining $(P=0.002)$, CL deposition $(P=0.007)$, increased tear meniscus height $(P=0.007)$, and decreased hydrogel nominal water content $(P=0.02)$. The wearing of SiHy lenses (as opposed to hydrogel lenses) was protective against corneal staining $(P=0.0004)$. Notably, these 
authors reported that neither CL care solutions nor disinfectants were associated with increased corneal staining.

Relatively little information is available relating corneal staining to discomfort. A paradox of the corneal staining response is that there appears to be no clear relationship between the severity of staining and the degree of ocular discomfort. For example, an exposure keratitis in the form of an extensive inferior arcuate diffuse staining pattern can be virtually asymptomatic, whereas a small tracking stain caused by a foreign body trapped beneath a rigid lens can be excruciatingly painful.

Studies examining corneal staining associated with the combination of various CL materials and solutions have produced equivocal results, with some studies showing no correlation between CLD and staining ${ }^{130-132}$ and others indicating that increased staining is associated with a reduction in lens comfort. ${ }^{133-135} \mathrm{~A}$ recent study, comparing dryness and corneal staining in a group of Asian and non-Asian wearers, ${ }^{136}$ demonstrated that the Asian subjects exhibited a greater amount of staining and reported a higher level of CLD. Among Asians, CLD and staining were not related, whereas they were among non-Asians.

Despite many publications examining corneal staining associated with CL wear, overall, there appears to be, at best, a weak link between CLD and corneal staining and it is not a major factor for most CL wearers.

\section{Stroma}

Keratocyte Density. Using LSCM, various authors have reported the normal keratocyte density in the anterior stroma to be approximately 993 cells $/ \mathrm{mm}^{2}$, or 29,917 cells $/ \mathrm{mm}^{3}$, decreasing toward the posterior stroma to approximately 621 cells $/ \mathrm{mm}^{2}$, or 18,733 cells $/ \mathrm{mm}^{3}$, an approximate $60 \%$ decrease in cells per area or volume. ${ }^{137}$ Also, keratocytes in the posterior stroma are less densely packed and overall their nuclei appear to be slightly larger and flatter than those in the anterior stroma. ${ }^{137}$ Keratocyte density does not differ between males and females or between right and left eyes of a subject. ${ }^{138}$ There is a decline in the density of keratocytes throughout the stroma with age, ${ }^{138,139}$ as well as an increase in the spacing of collagen fibers throughout life (by approximately $14 \%$ by age 90 years). ${ }^{140}$ The stroma also contains nerve fibers and microdots, which are small highly reflective dots found throughout this tissue layer. The composition of these microdots is unknown, but it has been hypothesized that they represent dysgenic or apoptotic cellular remnants lying dormant in the stroma. ${ }^{137}$

CL wear has an effect on keratocytes. Several studies have demonstrated an apparent loss of keratocyte density of approximately $18 \%$ to $30 \%$ in the anterior stroma and $7 \%$ to $18 \%$ in the posterior stroma, when wearing various lens types on either DW or EW schedules. ${ }^{91,141-143}$ The decrease in density was maintained when accounting for possible edema. ${ }^{141}$ However, not all studies have found this decrease. ${ }^{89,144}$ When a reduction has been noted, the density change was not affected by the Dk/t of the lens material. ${ }^{141,145}$ In a study examining the differences between no lens wear, SiHy lens wear, and high Dk/t rigid lens wear, Kallinikos and colleagues $^{146}$ found some reduction in keratocyte density in the anterior stroma with rigid lens wear, and in the posterior stroma with SiHy lenses compared with no lens wear. ${ }^{146}$ These authors suggested that this was due to the physical presence of the lens and perhaps mechanical stimulation of the release of epidermal growth factor and IL-8 from corneal epithelial cells. Loss of keratocytes may be more profound for SCL wearers compared with rigid gas permeable wearers. ${ }^{145}$ No reports have studied whether any change in keratocyte density is related to CLD.

Stromal Opacities. Apparently benign posterior stromal opacities or white dots have been reported in the corneas of CL wearers. ${ }^{137,147-150}$ These stromal opacities seen using slit lamp biomicroscopy may be related to the stromal microdots seen using LSCM. The microdots have a size of 1 to $4 \mu \mathrm{m} .{ }^{151,152}$ The initial contention that the appearance of the microdots was associated only with CL wear has been tempered by the finding that these can also be seen in the corneas of non-lens wearers, albeit to a lesser extent. ${ }^{137}$ The pathology and etiology of these formations is unknown. Although Brooks and colleagues ${ }^{148}$ and Hsu and colleagues ${ }^{153}$ noted that the development of deep stromal opacities was associated with ocular discomfort and photophobia, none of the other reports of deep stromal opacification or stromal microdots have reported any associated discomfort.

Stromal Infiltrates. CL wear may result in recruitment of cells into the cornea. These cells or "infiltrates" are presumed to be polymorphonuclear leukocytes (neutrophils) from the limbal vasculature, and this has been confirmed from corneal biopsies of $\mathrm{CL}$ wearers, with the adverse event named $\mathrm{CL}$ peripheral ulcer. ${ }^{154}$ While a review of adverse events with $\mathrm{CL}$ wear is beyond the scope of this article, infiltrates of the cornea can occur without symptoms and may occur even in the absence of lens wear. $^{155}$ The rate of asymptomatic infiltrates in the cornea of CL wearers appears to be influenced by wearing different combinations of SiHy lenses and multipurpose disinfecting solutions, ${ }^{156}$ although these results are equivocal. ${ }^{157}$

While infiltration of the cornea during overt adverse responses is associated with ocular symptoms, they may also be present in asymptomatic patients, indicating that there is not a straightforward relationship between low levels of corneal infiltration and comfort during CL wear.

Stromal Neovascularization. Wear of low Dk/t CLs may be associated with the ingrowth of blood vessels into the normally transparent cornea. ${ }^{158}$ This process of neovascularization is generally categorized as superficial or deep stromal. CL-induced neovascularization is asymptomatic and thus not related to CLD.

\section{Endothelium}

Endothelial Blebs. A phenomenon referred to as "endothelial blebs" can be observed in the endothelium of CL wearers. ${ }^{159}$ The appearance is of black, nonreflecting areas in the endothelial mosaic that correspond with the position of individual cells or groups of cells. Inagaki and colleagues ${ }^{160}$ compared the time course of endothelial bleb formation and disappearance between lenses of varying Dk/t in 20 subjects. Lenses of higher Dk/t induced the lowest bleb response and no difference was observed between rigid and soft lenses of similar $\mathrm{Dk} / \mathrm{t}$ values.

Histological studies of this response were conducted by Vannas and colleagues. ${ }^{161}$ The "blebbed" endothelium displayed edema of the nuclear area of cells, intracellular fluid vacuoles, and fluid spaces between cells. Thus, endothelial blebs appear to be the result of a local edema phenomenon, whereby the posterior surface of the endothelial cell bulges toward the aqueous. The endothelial cell bulges in this direction because this represents the path of least resistance, as Descemet's membrane provides much greater resistance to cell swelling than the aqueous humor. Light from the blebbed cell is reflected away from the observer, which explains why they appear dark or absent.

The etiology of endothelial blebs has been explained by Holden and colleagues. ${ }^{162}$ These authors attempted to induce 
blebs using a variety of stimulus conditions, and concluded that one physiological factor common to all successful attempts to form blebs was a local acidic $\mathrm{pH}$ change at the endothelium. Two separate factors induce an acidic shift in the cornea during CL wear ${ }^{128}$ : an increase in carbonic acid due to retardation of carbon dioxide efflux and increased levels of lactic acid as a result of lens-induced hypoxia and the consequent increase in anaerobic metabolism. When silicone elastomer lenses are worn, such metabolic changes do not take place because of their extremely high $\mathrm{Dk} / \mathrm{t}$. The time course of the appearance of blebs following lens insertion, and resolution following lens removal, is consistent with the time course of corneal $\mathrm{pH}$ change. ${ }^{163}$

Endothelial Cell Density. Numerous studies have demonstrated a decrease in corneal endothelial cell density in the central corneas of rigid ${ }^{164-167}$ and soft ${ }^{166,168-170}$ lens wearers. One possible explanation for the apparent CL-induced endothelial cell loss has been provided by Wiffen and colleagues, ${ }^{171}$ who compared central and peripheral corneal endothelial cell densities in non-lens wearing subjects and long-term CL wearers. Central cell density $(2723 \pm 366$ cells/ $\mathrm{mm}^{2}$ ) was found to be significantly higher than peripheral cell density $\left(2646 \pm 394\right.$ cells $\left./ \mathrm{mm}^{2}\right)$ for the non-lens wearing group, but not for the CL-wearing group (2855 \pm 428 cells/ $\mathrm{mm}^{2}$ central; $2844 \pm 494$ cells $/ \mathrm{mm}^{2}$ peripheral). Based on their results, Wiffen and colleagues ${ }^{171}$ suggested that CL wear causes a mild redistribution of endothelial cells from the central to the peripheral cornea. Thus, while there is no actual endothelial cell loss, there is a reduction in endothelial cell density in the central region of the cornea, which is counterbalanced by a commensurate increase in cell density in the corneal mid-periphery. The overall endothelial cell population of the cornea is therefore likely to be unaffected by CL wear and no reports exist of a correlation in cell density with CLD.

Endothelial Polymegethism. Polymegethism describes changes in endothelial cell size that occur such that the endothelial cells have a greater variation in cell size than normal, and is closely related to chronic hypoxia. ${ }^{172,173}$ Increases in corneal endothelial polymegethism are associated with the wear of polymethyl methacrylate (PMMA), ${ }^{144,164-167,174-178}$ rigid gas permeable, ${ }^{144,171,179,180}$ and conventional hydrogel ${ }^{88,166,169,171,177,178,181-185}$ lenses. However, SiHy ${ }^{168,186}$ and silicone elastomer ${ }^{187}$ lenses do not induce significant levels of polymegethism. It is likely that the etiology of endothelial polymegethism is the same as that for endothelial blebs, in which lens-induced hypoxia and hypercapnia causes an acidic shift at the endothelium, ${ }^{162}$ resulting in altered cell morphology. Thus, endothelial polymegethism represents a chronic response and endothelial blebs represent an acute response to the same stimuli.

The morphological changes that constitute polymegethism have been explained by Bergmanson, ${ }^{188}$ who conducted an ultrastructural study of the corneas of six long-term CL wearers. In normal circumstances, the lateral cell walls are extremely interdigitated. Bergmanson ${ }^{188}$ noted that CL wear causes the cell walls to reorient so that, rather than remaining normal to the endothelial surface, they straighten out and align obliquely. The interpretation of this observation in terms of the three-dimensional structure of the endothelium is that endothelial cells have changed shape but the volume of each cell remains constant. By observing only the apical surface of the endothelium on specular reflection, it appears that a disparity in cell size has developed, whereas, in reality, the cells have merely become reoriented in three-dimensional space.

A further observation of Bergmanson ${ }^{188}$ is that, although the endothelium of CL wearers showed some inter- and intracellular edema, the cells were otherwise of a healthy appearance, containing normal organelles. This raises the possibility that, rather than representing an adverse effect, endothelial polymegethism is a nonproblematic adaptation to chronic metabolic stress induced by CLs.

Sweeney ${ }^{177}$ has drawn an anecdotal association between endothelial polymegethism and a condition that she termed "corneal exhaustion syndrome." This is a condition in which patients who have worn hydrogel CLs for many years suddenly develop a severe intolerance to lens wear, characterized by CLD, reduced vision, photophobia, and an excessive edema response. These patients also displayed a distorted endothelial mosaic and moderate to severe polymegethism. Although the link between endothelial polymegethism and corneal exhaustion syndrome is not proven, it does appear that certain wearers can develop an intolerance of lenses over time as a response to chronic and severe lens-induced hypoxia. However, this is unlikely with modern CL materials and the link between hypoxia and CLD remains tenuous.

Endothelial Permeability. There is disagreement in the literature as to whether CL wear alters endothelial permeability. Dutt and colleagues ${ }^{189}$ reported a significant increase in mean endothelial permeability, measured using corneal fluorophotometry, among CL wearers, indicating a defect in their endothelial barrier function. A significant increase in the mean endothelial pump rate was also noted among CL wearers. Using similar techniques, Chang and colleagues ${ }^{184}$ reported decreased endothelial permeability among CL wearers. In contrast, Bourne ${ }^{190}$ reported that the relative endothelial pump rate of 20 long-term CL wearers did not differ significantly from that of control subjects.

Despite these many alterations to the endothelium, to date there have been no reports of CLD associated with nonsevere endothelial cell changes.

\section{Limbus}

Limbal Structure. The limbus is a ring of tissue approximately $1.5 \mathrm{~mm}$ wide that marks the transition between the clear cornea and the sclera. ${ }^{191}$ The epithelium thickens on passing from the cornea to limbus and the number of cell layers increases to approximately $10^{192,193}$ and become arranged into a parallel series of radially disposed bars, separated by a vascular connective tissue. ${ }^{194}$ These are the palisades of Vogt. ${ }^{195}$ Visibility of the palisades at the slit-lamp is greatly enhanced in pigmented eyes, where the epithelial bars are outlined by pigmented basal cells. The vessels of the palisades arise from an episcleral vascular "circle," which also gives rise to the anterior conjunctival arteries and to the subepithelial marginal arcades of the cornea. ${ }^{196,197}$ The latter vessels form a series of vascular loops that surround the corneal periphery, their central tips providing a useful surface landmark for the periphery of Bowman's layer. They can be the source of superficial new vessels, arising as a pathological response to CL wear or to corneal injury, inflammation, or infection.

Basal, niche-like regions of the epithelial palisades house the stem cells of the cornea, whose division maintains the corneal epithelium. ${ }^{198,199}$ These cells divide infrequently in the normal cornea but give rise to daughter, transient amplifying cells, ${ }^{200}$ which migrate centripetally from the limbus to the cornea. Their further progeny migrate to the surface and undergo apoptosis prior to shedding.

Limbal Redness. The limbus can respond to CL wear by engorging the limbal vasculature, which is usually referred to as "limbal redness." During wear of low Dk/t SCL, the number of vessels filled with blood and the extent of filling increases, but this does not happen during wear of PMMA lenses, ${ }^{201}$ suggesting that the response is local and not affected by hypoxia occurring at the central cornea. Papas ${ }^{202}$ demonstrat- 
ed that when eyes were exposed to anoxic conditions (100\% nitrogen in goggles), the limbal vasculature responded by increasing blood flow, resulting in increased redness. Sustained increases in limbal redness during wear of low Dk/t lenses may lead to growth of limbal vessels into the cornea, which is considered to be an adverse response to lens wear. Wear of low $\mathrm{Dk} / \mathrm{t}$ soft lenses for 9 months on an EW schedule results in a significant increase in neovascularization. ${ }^{203}$

With the advent of SiHy lenses, the number of studies examining limbal redness increased, with studies demonstrating no difference in limbal redness during wear of high $\mathrm{Dk} / \mathrm{t}$ SiHy lenses compared with no lens wear. ${ }^{204}$ Use of low Dk/t soft lenses on a daily disposable basis resulted in higher levels of limbal redness than that determined when wearing two types of high Dk/t silicone hydrogel lenses. ${ }^{205}$ During EW, low Dk/t hydrogel lens wearers showed significantly higher levels of limbal redness than high Dk/t SiHy lens wearers. ${ }^{203}$ Refitting subjects from low Dk/t hydrogel lenses to high Dk/t SiHy lenses in either DW or EW schedules results in a significant decrease in limbal redness after just a few weeks. ${ }^{206-209}$ Refitting subjects with high Dk/t lenses also results in reduced signs of corneal neovascularization. ${ }^{210-212} \mathrm{High}$ Dk/t lenses do not induce changes to limbal redness even after 3 years of EW. ${ }^{213}$

There is little evidence that limbal redness is related to CLD. While one study showed an improvement in comfort during lens wear after refitting with high Dk/t SiHy lenses and a corresponding decrease in limbal redness, ${ }^{212}$ another study demonstrated a similar improvement in comfort (but not limbal redness) even after refitting high $\mathrm{Dk} / \mathrm{t}$ lens wearers into low Dk/t daily disposable hydrogel lenses. ${ }^{214}$ The type of SiHy lens worn makes a difference to comfort, even though there may be no difference in clinical scores of limbal redness, ${ }^{215}$ and while wearing a low Dk/t lens on a daily disposable basis resulted in increased limbal redness compared with wearing high $\mathrm{Dk} / \mathrm{t}$ lenses on the same schedule, there was no relationship to comfort, ${ }^{205}$ suggesting that factors other than oxygen permeability (and, thus, limbal redness) are more important in the factors that drive the comfort response.

Limbal Stem Cell Deficiency. Limbal stem cells serve as the source for corneal epithelial cells, thus stem cell deficiency leads to an abnormal corneal surface, which exhibits fluorescein staining and a dull irregular reflex, often accompanied by decreased vision. ${ }^{216}$ Other complications include photophobia, inflammation, hyperemia, recurrent or persistent epithelial defects, conjunctivalization, scarring, and ulceration. ${ }^{216}$ Several studies show that SCL wear may result in stem cell deficiency. ${ }^{216-229}$ The condition may be focal, affecting a small area, or, more rarely, occur as a severe, almost total stem cell loss. ${ }^{216,229}$ It has been suggested that the more severe form is the result of additional pathology to a cell population already stressed by years of lens wear that finally "exhausts" the stem cells. ${ }^{229}$ The true cause of the stem cell deficiency remains unknown, but it has been proposed that it may result from hypoxia and/or mechanical friction on the limbal tissue. ${ }^{216,220,228}$

In a retrospective study of almost 600 SCL wearers, $2.4 \%$ of subjects were found to have focal limbal stem cell deficiency, ${ }^{221}$ with approximately one-third being symptomatic, suggesting that the condition is more common than one would expect and often goes undetected. ${ }^{216}$ Notably, the preponderance of subjects were female. ${ }^{216,221,229}$ Prolonged wear (both hours per day and numbers of years of wear) may also be a contributing factor. ${ }^{216,229}$ At least two studies show that the epitheliopathy resulting from this deficiency was primarily present in the superior cornea. ${ }^{216,221}$ Rigid gas permeable and scleral lenses do not cause limbal stem cell deficiency; indeed, these lenses have been reported as having beneficial effects in the management of corneal conjunctivalization and in the reversal of stem cell deficiency. ${ }^{230,231}$ As yet there is no evidence for changes in limbal stem cells being related to CLD, and it seems unlikely that this could account for the acute form of CLD that occurs toward the end of the day, after as little as 1 day of wear in a neophyte wearer.

\section{Corneal Edema}

All CLs induce some level of edema, including silicone elastomer lenses, which have extremely high $\mathrm{Dk} / \mathrm{t}$ values. ${ }^{232}$ CLs restrict corneal oxygen availability, ${ }^{128,233,234}$ creating a hypoxic environment at the anterior corneal surface. To conserve energy, the corneal epithelium begins to respire anaerobically. Lactate, a byproduct of anaerobic metabolism, increases in concentration and moves posteriorly into the corneal stroma. This creates an osmotic load that is balanced by an increased movement of water into the stroma. The sudden influx of water cannot be matched by the removal of water from the stroma by the endothelial pump, resulting in corneal edema and corneal thickening. ${ }^{235,236} \mathrm{~A}$ number of other possible mechanisms have been suggested as playing a role in lens-induced corneal edema, including retardation of carbon dioxide efflux (leading to tissue acidosis), ${ }^{128}$ mechanical effects, ${ }^{237}$ temperature changes, ${ }^{238}$ hypotonicity, ${ }^{239}$ and inflammation. ${ }^{240}$ Nguyen and colleagues ${ }^{241}$ have shown that the variability in CL-induced corneal swelling is associated with both corneal metabolic activity and endothelial function. This suggests that individuals with larger levels of corneal metabolic activity produce more lactic acid and thus more swelling.

The amount of edema is related primarily to the extent of corneal hypoxia that is induced by the lens. With low Dk/t hydrogel and rigid lenses, daytime central corneal edema typically varies between $1 \%$ and $6 \%,{ }^{242}$ and the level of overnight central edema measured on awakening generally falls in the range $10 \%$ to $15 \% .{ }^{243}$ SiHy lenses induce less than $3 \%$ overnight central corneal edema, ${ }^{244}$ which is similar to the level of overnight edema without lenses.

While corneal swelling represents both a chronic and acute response to hypoxia, epithelial microcysts are considered to be an important indicator of chronic metabolic stress in the corneal epithelium in response to wearing low Dk/t lenses. Bergmanson $^{245}$ postulated that microcysts represent an extracellular accumulation of broken down cellular material trapped in the basal epithelial layers. In a process similar to that which occurs in Cogan's microcystic dystrophy, ${ }^{246}$ the epithelial basement membrane reduplicates and folds, forming intraepithelial sheets that eventually detach from the basement membrane and encapsulate the cellular debris. There is no proven association of epithelial microcysts with CLD.

Dillehay ${ }^{247}$ argued that increasing levels of available oxygen during CL wear lead to improved comfort. However, these arguments were based largely on anecdotal information. No concrete evidence exists linking oxygen availability or the level of corneal edema during CL wear with CLD, and a recent review supports this. ${ }^{248}$

\section{Shape Changes}

Videokeratographic corneal mapping techniques reveal that all forms of CL wear are capable of inducing small, but statistically significant, changes in corneal topography. ${ }^{249-252}$ Ruiz-Montenegro and colleagues ${ }^{249}$ reported the prevalence of abnormalities in corneal shape to be $8 \%$ in a control group of non-CL wearers, versus $75 \%$ in PMMA lens wearers, $57 \%$ in DW rigid lens wearers, $31 \%$ in DW hydrogel lens wearers, and $23 \%$ in $\mathrm{EW}$ hydrogel lens wearers.

The results of studies investigating corneal shape changes with SiHy lenses are equivocal. Various authors failed to observe 
corneal curvature changes in subjects wearing low-253-255 and high-modulus ${ }^{253,254}$ SiHy lenses, during observation periods ranging from 1 to 18 months. However, Dumbleton and colleagues $^{256}$ observed a small degree of central corneal flattening in both major meridians of 0.35 diopters (D) in subjects wearing high-modulus SiHy lenses over a 9-month period. Gonzalez-Meijome and colleagues ${ }^{250}$ noted a similar phenomenon in SiHy lens wearers over a 12-month wearing period. Maldonado-Codina and colleagues ${ }^{257}$ noted that, over a 12-month period of continuous wear, corneal curvature of subjects wearing high-Dk/t rigid lenses became flatter by 0.13 $\mathrm{mm}$, compared with $0.04 \mathrm{~mm}$ for subjects wearing high-Dk/t SiHy lenses $(P=0.0003)$. The refractive findings in subjects wearing these lenses mirrored the corneal curvature changes.

Shape changes may also be induced by lens "binding," in which the lens becomes immobile, which may occur with DW and $\mathrm{EW}$ of rigid lenses. Based on subject reports, lens binding occurs in $29 \%$ of $\mathrm{DW}^{258}$ and $50 \%$ of $\mathrm{EW}^{259}$ rigid lens subjects. Most other forms of lens-induced corneal shape change are either rare or are known to be associated with specific types of poorly designed or ill-fitting lenses. ${ }^{260}$

Corneal curvature changes in orthokeratology are deliberately induced to obtain a refractive effect, and appear to result from a combination of short-term corneal molding and a longerterm redistribution of anterior corneal tissue. ${ }^{261,262}$ It has also been suggested that the tear reservoir generated by the steeper secondary curves leads to pressure changes that are responsible for the corneal tissue redistribution. ${ }^{262,263}$

To date, there are no reports linking CL-induced corneal shape change to CLD.

\section{Temperature Change}

Purslow and colleagues ${ }^{264}$ used a noncontact infrared camera to record the ocular surface temperature (OST) in subjects wearing hydrogel and SiHy CLs on a DW and EW basis. They found that OST immediately following CL wear was significantly greater compared to non-lens wearers $\left(37.1 \pm 1.7^{\circ} \mathrm{C}\right.$ vs. $35.0 \pm 1.1^{\circ} \mathrm{C}$; $P<0.005)$. Lens surface temperature was highly correlated to, but lower than, OST (by $-0.62 \pm 0.3^{\circ} \mathrm{C}$ ). There was no difference with modality of wear, but significant differences were found between the hydrogel and SiHy lens materials (35.3 $\pm 1.1^{\circ} \mathrm{C}$ vs. $\left.37.5 \pm 1.5^{\circ} \mathrm{C} ; P<0.0005\right)$. The authors concluded that OST is greater with hydrogel and greater still with SiHy CLs in situ, regardless of modality of wear, and concluded that the effect is likely due to the thermal transmission properties of the CL material.

Whereas Purslow and colleagues ${ }^{264}$ assessed OST immediately following CL wear, Ooi and colleagues ${ }^{265}$ developed a twodimensional simulation of heat propagation in the human eye using finite element analysis to estimate OST during CL wear. In contrast to Purslow and colleagues, ${ }^{264}$ they calculated that the corneal surface temperature during CL wear decreased by an average of $0.52 \pm 0.05^{\circ} \mathrm{C}$ compared with a bare cornea, for all lens types. The authors suggested that an increase in evaporation rate when a CL is worn increases the cooling effect on the ocular surface, resulting in a lower corneal surface temperature during lens wear. Neither of the above groups who examined OST changes with CL wear examined any link to CLD.

\section{Impact of CLs on the ConJunctiva}

\section{Bulbar Conjunctiva}

Conjunctival Staining. Dyes that have been used to assess conjunctival staining include sodium fluorescein, rose Bengal, and lissamine green. In SCL wearers, conjunctival staining is often observed approximately $2 \mathrm{~mm}$ from the limbus, coinciding with the SCL edge. ${ }^{266}$ This is thought to be due to CL movement or changes in tear film characteristics at the lens edge. ${ }^{267}$

Several studies have shown greater conjunctival staining with CL wear compared with no CL wear. Lakkis and colleagues $^{268}$ showed a significantly higher level of conjunctival staining in hydrogel wear compared to non-lens wearers, and found this to correlate with dryness and itchiness. Maldonado-Codina and colleagues ${ }^{267}$ showed greater conjunctival staining with two SiHy lenses compared with no lens wear or hydrogel lens wear. In a retrospective analysis of 338 experienced lens wearers, Brautaset ${ }^{118}$ found conjunctival staining in one-third of subjects. Morgan and colleagues ${ }^{269}$ found significantly greater conjunctival staining in a group of 35 neophytes fitted with SiHy daily disposable lenses compared with non-lens wearers, and this was the only clinical parameter measured to change significantly with lens wear. Guillon and Maissa ${ }^{270}$ assessed conjunctival staining and comfort in CL wearers using lissamine green. They found greater conjunctival staining in symptomatic subjects both with and without lens wear. These authors suggest that the pattern of staining indicates that the CL causes changes to the conjunctiva in areas not only confined to the lens edge, which they attributed to evaporation due to destabilization of the tear film by the CL. ${ }^{270}$

Various hypotheses have been postulated regarding CLinduced conjunctival staining, including changes to lens parameters with lens wear (Meadows DL, et al. IOVS 2009;50:ARVO E-Abstract 5652), CL modulus (Meadows DL, et al. IOVS 2009;50:ARVO E-Abstract 5652), poor lens fit (Meadows DL, et al. IOVS 2009;50:ARVO E-Abstract 5652), ${ }^{271}$ or poor edge design. ${ }^{266}$ Meadows and colleagues (Meadows DL, et al. IOVS 2009;50:ARVO E-Abstract 5652) found that changing the lens material and fit impacted the level of conjunctival staining, whereas changing solution did not make a difference. Ozkan and colleagues ${ }^{272}$ correlated changes to lens parameters with conjunctival staining. They showed a decrease in diameter with lens wear and increasing temperature, both in vivo and ex vivo, which did not correlate with comfort or conjunctival staining. ${ }^{272}$ They were able to show that lenses with a "knife" or "chisel" edge-form caused more staining than a lens with a relatively "round" edge design. However, no significant difference in comfort was found between edge types after 1 week of wear and there was no correlation between conjunctival staining and comfort, or conjunctival staining and bulbar or limbal redness. ${ }^{272}$ This is in agreement with Maissa and colleagues, ${ }^{266}$ who showed that conjunctival staining is most severe nasally and least severe superiorly, a factor they attribute to the flatter conjunctival topography in the nasal quadrant.

In rigid CL wearers, 3 and 9 o'clock corneal staining is visualized with the instillation of fluorescein, and is often accompanied by bulbar and limbal hyperemia and conjunctival staining. Greater inferior conjunctival staining in rigid $\mathrm{CL}$ wearers has been reported in a retrospective study by Swarbrick and Holden. ${ }^{120}$ Van der Worp and colleagues ${ }^{273}$ showed that eyes with conjunctival staining demonstrated more corneal staining, compared with those with no conjunctival staining. Symptoms were more frequently reported in those with conjunctival staining, compared with those without. ${ }^{273}$

Conjunctival Flaps. The incorporation of silicone components into SCL materials, which increases the lens Dk/t, results in materials with higher modulus values. ${ }^{274}$ As a result, mechanical complications with SiHy materials are greater than those encountered with lower modulus hydrogel materials. ${ }^{110,112,275}$ One of these complications has been termed "conjunctival flaps." $112,276-280$ These have been described as 
"irregular free ends of the conjunctival tissue which move with blinking or other digital manipulation." 278

Conjunctival flaps are typically found $1.5 \mathrm{~mm}$ from the limbus in CL wearers and have been reported to resolve with lens discontinuation (Markoulli M, et al. IOVS 2007; 43:ARVO E-Abstract 5391). Graham and colleagues ${ }^{279}$ found a $39 \%$ occurrence of conjunctival flaps in EW with SiHy lenses, whereas Santodomingo and colleagues ${ }^{280}$ reported a higher incidence with lotrafilcon A compared with balafilcon A and more events when lenses were worn overnight. Bergmanson and colleagues ${ }^{277}$ performed conjunctival impression cytology (CIC) on three non-CL wearers, three CL wearers with conjunctival flaps, and three CL wearers without conjunctival flaps. All CL wearers were fitted with lotrafilcon A in the 8.4-mm base curve. These authors found the samples taken over the conjunctival flap to consist of multilayers of epithelial cells and goblet cells and to be devoid of inflammatory cells. In contrast, the nonflap groups had only a single layer of epithelial cells. The authors conclude that conjunctival flaps consist of essentially healthy tissue that has been displaced by the $\mathrm{CL}$ edge. ${ }^{277}$ A biopsy study of the conjunctival tissue in the region of the conjunctival flap, compared with nonflap tissue in the same eye, supports the findings of the CIC study, that indeed there is no sign of inflammation. ${ }^{278}$ While the exact etiology of conjunctival flaps remains unknown, one compelling hypothesis put forward by Bergmanson and colleagues ${ }^{277}$ is that the mechanical effect of the lens edge results in a "snow plough" effect, where the CL "shovels" piles of epithelial cells aside. These cells form new desmosomal junctions to each other, but lose their connection to the underlying tissue, except to the side that they remain adherent.

The clinical impact of conjunctival flaps is currently unclear and it is not known whether their detection requires lens wear discontinuation until resolution. From the literature available to date it would appear not, although flaps may be an indication of a poor-fitting CL, ${ }^{277}$ which could require a change of lens modulus, edge design, base curve, or wear schedule. There appears to be no correlation between CLD and conjunctival flaps.

Lid Parallel Conjunctival Folds. Lid parallel conjunctival folds (LIPCOFs) are subclinical parallel folds of the lower bulbar conjunctiva, parallel to the lower lid margin and have been found to be present in dry eye, but are not age-related. ${ }^{281}$ Pult and colleagues ${ }^{282}$ showed that lid wiper epitheliopathy (LWE) and LIPCOF correlated with dryness in CL wearers, but other clinical factors, such as corneal staining, bulbar redness, or tear break-up time, did not correlate. The authors suggest that this could be due to a similar etiology of friction. The correlation among LIPCOF, reduced tear film stability, and LWE could be suggestive of a mechanical etiology. ${ }^{282}$ LWE also correlated positively with bulbar redness, suggesting that irritation from lens fit or other factors may be related to their development. $^{282}$

Conjunctivochalasis. Conjunctivochalasis has been defined as the redundant, loose, nonedematous conjunctival tissue found at the lower eyelid, typically in older people. Because of its location at the position of the tear prism, it is thought that the presence of conjunctivochalasis can disturb the distribution of the tear film. Increased matrix metalloproteinase expression has been reported in the fibroblasts of conjunctivochalasis, suggesting that this is a result of collagen degradation. ${ }^{283}$ In support of this hypothesis, Zhang and colleagues, ${ }^{284}$ using optical coherence tomography, found reduced conjunctival thickness in those with conjunctivochalasis and in older subjects. Mimura and colleagues ${ }^{285}$ reported an increase in conjunctivochalasis with increasing duration of CL wear. No reports linking CLD and conjunctivochalasis exist.

Hyperemia. Increased bulbar hyperemia has been reported in asymptomatic CL wear, in wearers of both rigid and
SCLs. ${ }^{267}$ Both subjective and objective assessment of bulbar conjunctival vasculature did not show a significant progressive change with SCL wear over a 10 -month period. ${ }^{286} \mathrm{~A}$ significant difference was found in the rigid wearers in the temporal bulbar conjunctiva after 4 months of wear, a factor that was attributed to adaptation to rigid lens wear. ${ }^{286}$ Cheung and colleagues ${ }^{287}$ hypothesized that CL use causes damage to the conjunctival microvasculature by direct vasoocclusion, due to damage to the conjunctival vessels or to the conjunctiva itself. These investigators compared the abnormalities in the conjunctival microvasculature of CL wearers with at least 2 years of experience with non-CL wearers. They found significantly higher abnormalities in CL users as opposed to non-CL wearers, and reported increased vessel diameter and changes to vessel contour in the region of the CL edge. ${ }^{287}$

Conjunctival Squamous Metaplasia. CL wear can induce distinct changes to the conjunctiva around the limbus, characterized by conjunctival squamous metaplasia (i.e., flattening of epithelial cell shape and enlarged cell diameter with loss of goblet cells) ${ }^{288}$ and alterations to the nuclei of cells that has been termed "snake-like chromatin"289 (Figs. 2, 3). This was observed in all CL wearers in the first systematic and prospective studies on conjunctival cytology in CL wearers by Knop and Brewitt. 290,291 These changes are believed to occur as a result of mechanical friction on the epithelial cell surface, and may be reversed by cessation of lens wear. ${ }^{288}$

Studies by Adar and colleagues ${ }^{292}$ and Sengor and colleagues $^{293}$ confirmed that almost all CL wearers have varying degrees of squamous metaplasia. Simon and colleagues ${ }^{294}$ investigated the correlation between severity of cytological alterations and symptoms in wearers of SCLs and rigid gas permeable CLs. They found that $60 \%$ of symptomatic CL wearers had cytological alterations after 6 months of CL wear, which increased in severity with duration of CL wear and occurred at a higher prevalence and severity in symptomatic compared with asymptomatic CL wearers. This supports similar findings from Adar and colleagues, ${ }^{292}$ who observed in a population of soft and rigid CL wearers that $60 \%$ of $\mathrm{CL}$ wearers had minor complaints and that the presence of complaints was related to a higher prevalence and severity of cytologic changes in such subjects.

These two studies support a potential causative link between cytological alterations in CL wear and CLD. In asymptomatic subjects, none of the rigid gas permeable wearers and one-third of the SCL wearers had abnormal CIC samples, possibly due to differences in fit between these lens types. In a prospective study, ${ }^{288}$ it was observed that conjunctival squamous metaplasia was evident after only 2 weeks of CL wear. The extent of alterations appeared to reach a plateau within 6 months of CL wear, as later confirmed by another study, ${ }^{294}$ although a longer study time would be necessary to verify this. After CL wear ceased, the cytological conjunctival changes proved to be reversible, although this took much longer (up to 2 years) than their induction in the first case. ${ }^{288}$ This finding obviously argues against a strong association with CLD, as CLD is rapidly relieved by removal of the lens from the eye.

Goblet Cell Density. Goblet cell density (GCD) is potentially an important morphological factor in CL wear because the mucin they secrete, ${ }^{30,295,296}$ along with lubricating proteins, ${ }^{297}$ is conceivably important for their ability to reduce friction on the ocular surface, which could be linked to CLD.

CL-induced changes in GCD, as identified by CIC, have been summarized by Doughty. ${ }^{298}$ This review indicated that most published studies concluded that CL wear results in a decrease in goblet cells in the conjunctiva, but the data are equivocal, with several studies showing no change or indeed an increase. 


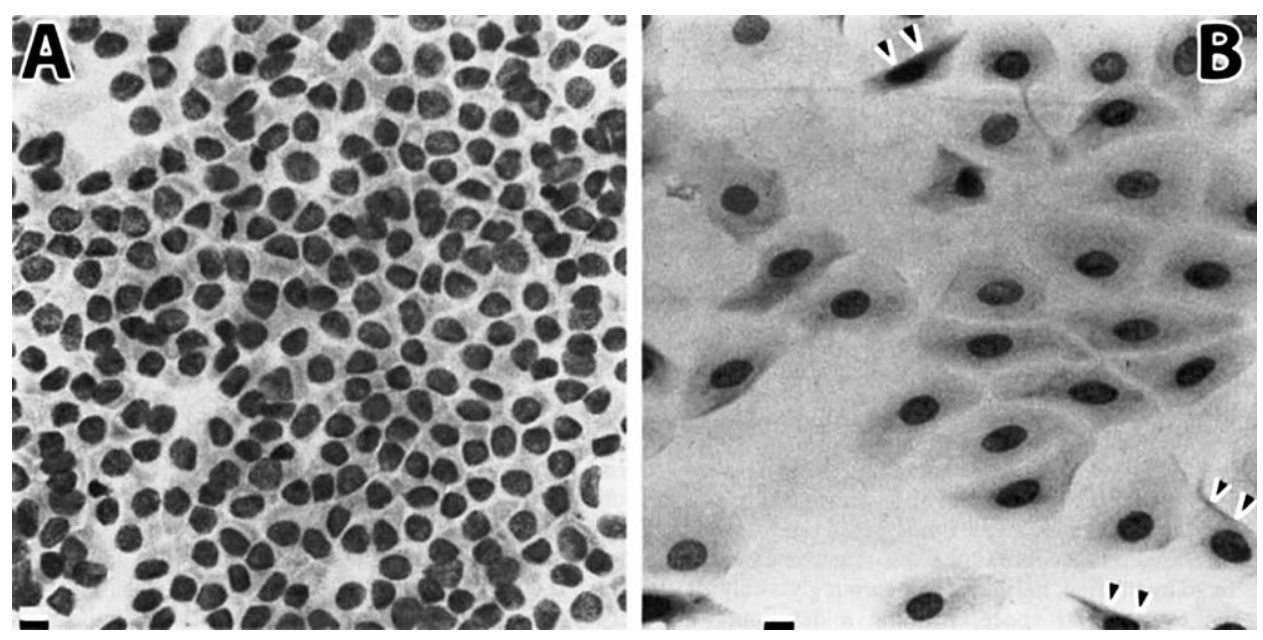

Figure 2. Conjunctival epithelial changes (squamous metaplasia) in CL wearers. After start of CL wear, a rapid change of the normal small cuboidal cell shape ([A] nucleo/cytoplasmic [n/c] ratio of approximately 1:1) into flat cells with enlarged diameter ([B] n/c ratio of approximately 1:5-1:8 or more) occurs in the bulbar conjunctiva, within the excursion zone of the lens. Double arrowheads in (B) indicate folding of flattened cell margins. Light microscopy; scale bars: $10 \mu \mathrm{m}$. Reprinted with permission from Knop E, Brewitt H. Morphology of the conjunctival epithelium in spectacle and contact lens wearers-a light and electron microscopic study. Contactologia. 1992;14E:108-120. Copyright 1992 Georg Thieme Verlag.

This work highlighted the need for more objective and repeatable means by which to assess GCD by CIC. ${ }^{298-299}$

Potential reasons for variations in GCD when assessed by CIC have been well described. ${ }^{288,301,302}$ Variations in results are related to a number of factors, including differences in sampling location, methodology to collect the sample, grading scale used to assess the collected tissue for squamous metaplasia, and field of view used to examine the tissue collected. $288,299,300,302-304$ One major issue when attempting to differentiate changes in GCD over time relates to the fact that in the perilimbal 12 o'clock position, which is the location used in many studies to conduct CIC, GCD changes dramatically within just a few millimeters. ${ }^{288,305}$ Thus, even a small alteration in the location at which the CIC is conducted could produce very different results, without being related to true changes in GCD.

One other method that shows some promise for evaluating conjunctival changes is LSCM. Efron and colleagues ${ }^{306}$ performed in vivo LSCM on the bulbar conjunctiva of 11 healthy non-CL wearers and 11 asymptomatic CL wearers. The authors found greater conjunctival epithelial cell density in CL wearers in all cardinal positions compared with the non-lens wearing counterparts, but a reduced conjunctival epithelial thickness in lens wearers. The authors attribute this thinning to
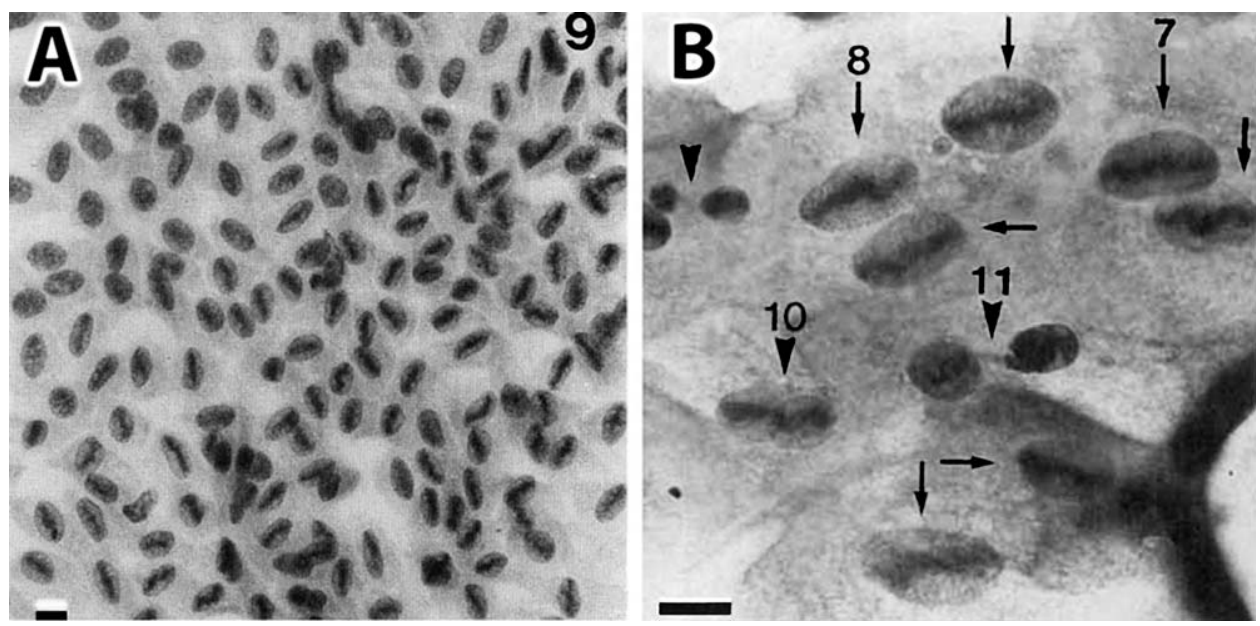

Figure 3. Conjunctival epithelial changes in CL wearers show a peculiar rearrangement of the nuclear chromatin ("snake-like chromatin"). Light microscopy overview (A) shows a group of such cells that are arranged similar to a fish "swarm," here in a 7 to 1 o'clock direction. Increased magnification (B) shows individual flattened cells and nuclei with different stages of snake-like chromatin. Chromatin material, detached from the nuclear periphery, forms a central elongated structure that is first bar-shaped (nucleus " 7 " in $[\mathbf{B}]$ ) and later undulated (nucleus " 8 " in $[\mathbf{B}]$ ). Advanced stages develop a central segmentation (nuclei "10," "11" in $[\mathbf{B}]$ ). The accumulation of chromatin in the long axis of the nucleus together with later segmentation of the nucleus by cytoplasmic filaments that are rolled around it indicate the presence of chronic mechanical friction at the ocular surface of lens wearers that is conceivably related to CLD. Light microscopy; scale bars: $10 \mu \mathrm{m}$. (A) Reprinted with permission from Knop E, Brewitt H. Morphology of the conjunctival epithelium in spectacle and contact lens wearers-a light and electron microscopic study. Contactologia. 1992;14E:108-120. (B) Reprinted from Knop E, Reale E. Fine structure and significance of snakelike chromatin in conjunctival epithelial cells. Invest Ophthalmol Vis Sci. 1994;35:711-719.375 
a similar mechanism to that seen in corneal thinning in CL wear, as a result of mechanical and metabolic effects. The increased density was attributed to the delayed desquamation as a result of lens wear. GCD was not found to differ between the two groups.

To date, data linking GCD to CLD are lacking, but potentially worthy of future evaluation, particularly around the lid wiper region. Studies should examine the time course of GCD, and whether this links to CLD, or if the magnitude of GCD is linked to the severity of CLD.

\section{Palpebral Conjunctiva}

The palpebral conjunctiva plays an important role in controlling the interaction with the ocular surface and the CL. Slitlamp examination of the upper tarsal conjunctiva reveals a pink mucous membrane with a satin-like, or a fine, uniform papillary appearance. Allansmith ${ }^{307}$ reported that $14 \%$ of nonCL wearers had a satin-smooth conjunctival appearance of the upper tarsal plate, $85 \%$ had small uniform papillae, and $1 \%$ had nonuniform papillae. Korb and colleagues ${ }^{308}$ reported that $0.6 \%$ of healthy subjects showed conjunctival papillae of more than $0.3 \mathrm{~mm}$ on the upper tarsal conjunctiva.

$\mathrm{CL}$ wear is known to induce CL papillary conjunctivitis (CLPC) in some wearers, which was first noted by Spring. ${ }^{309}$ It is a papillary reaction on the upper tarsal conjunctiva accompanied by discomfort and mucous production. The condition has been described in detail by Allansmith and colleagues, ${ }^{310-312}$ and has been associated with both soft and rigid CL wear and can lead to CL intolerance and discontinuation of wear. The term "giant papillary conjunctivitis" is more general and indicates a noninfectious inflammatory disorder involving the superior tarsal conjunctiva with the presence of papillae measuring $0.3 \mathrm{~mm}$ or larger.

While subjects with overt CLPC will be symptomatic, there have been no direct reports linking CLD with general, nonpathological changes to the palpebral conjunctiva. However, the use of sensitive grading scales ${ }^{313,314}$ may be useful in detecting subtle changes to the palpebral conjunctiva, and may be useful in linking palpebral conjunctival changes with CLD. In one study that examined differences in comfort response and slit-lamp findings between two groups of CL wearers using different multipurpose disinfecting solutions, there was a possible effect of palpebral roughness on the symptoms of grittiness and scratchiness during CL wear. $^{315}$

\section{Impact of CLs on Meibomian Glands}

The meibomian glands are large sebaceous glands that are located in the tarsal plates of the eyelids ${ }^{316,317}$ and produce the lipids that serve, as the outermost layer of the preocular tear film, to retard evaporation of the aqueous phase of the tears. $^{318}$ Meibomian gland dysfunction (MGD) is a chronic, diffuse abnormality of the meibomian glands, commonly characterized by terminal duct obstruction and/or qualitative/ quantitative changes in the glandular secretion. This may result in alteration of the tear film, symptoms of eye irritation, clinically apparent inflammation, and ocular surface disease. ${ }^{319}$

There is a long-standing clinical impression that CL wear increases the risk of MGD. Korb and Henriquez ${ }^{320,321}$ investigated the meibomian glands of individuals with a primary complaint of CL intolerance. They described clinical and cytological evidence indicating that the syndrome is due to obstruction of the meibomian gland orifices by desquamated epithelial cells that tend to aggregate in keratotic clusters, resulting in changes in the meibomian gland contribution to the precorneal tear film.

Several studies have reported the prevalence of MGD in CL and non-CL wearers. ${ }^{320,322-324}$ A meta-analysis of such studies $^{325}$ revealed that the prevalence did not differ significantly between the two groups, thus suggesting that CL wear may not increase the risk for MGD. This could be because many of these studies employed small sample sizes and used a wide variety of methods to confirm MGD.

In contrast, Arita and colleagues ${ }^{326}$ provided direct evidence that CL wear may affect the morphology of meibomian glands. Morphological observation of the meibomian glands revealed that the frequency of meibomian gland loss was significantly higher in CL wearers compared with non-lens wearers. These results strongly suggest that CL wear is a potential cause of alteration in meibomian glands, and may result in MGD.

\section{Meibomian Gland Orifice Changes}

Foaming of the lower tear meniscus, especially toward the outer canthus, is sometimes observed in individuals with CLassociated MGD. ${ }^{320,322}$ Korb and Henriquez ${ }^{320}$ found that foaming on the lower lid margins was apparent in $66.2 \%$ of symptomatic CL wearers but in only $3.7 \%$ of asymptomatic CL wearers $(P<0.0001)$. Hypersecretory CL-associated MGD is characterized by the release of a large volume of meibomian lipid (meibum) at the lid margin (foaming) in response to pressure on the tarsus. It remains unclear, however, whether the increased amount of lipid is the result of true hypersecretion, or the damming back of mildly obstructed secretions. ${ }^{319}$ Long-standing cases of CL-associated MGD may be linked to lid margin abnormalities, such as vascularization, morphological irregularity of the lid margin, blockage (plugging) of orifices, and damage to the mucocutaneous junction. ${ }^{327}$ In severe cases, in which the meibomian gland orifices are blocked, there is an absence of glandular secretion. Symptomatic CL wearers in whom lid margin abnormalities are not apparent may have a condition referred to as "nonobvious MGD."328

\section{Morphological Changes of Meibomian Glands}

Some studies have found no relation between meibomian gland dropout and CL wear. ${ }^{329,330}$ However, these studies examined only the glands in the central area of the lower eyelid, which may not necessarily reflect meibomian gland changes across the full width of the lid margin. Arita and colleagues $^{331}$ use a noninvasive meibography system that allows observation of the meibomian glands in both upper and lower eyelids (Fig. 4). They found that CL wear likely affects the morphology of meibomian glands, with the effects being greater on meibomian glands throughout the upper eyelid than on those in the lower eyelid. ${ }^{326}$ Partial or complete loss of the meibomian glands in each eyelid was significantly higher for CL wearers than for control individuals. The length of the affected meibomian glands was less than half that observed for normal glands. These patterns of meibomian gland changes were rarely detected in non-lens wearers, and suggest that CL wear is a potential cause of MGD.

The results of Arita and colleagues ${ }^{326}$ also suggested that CL wear produces different effects on the upper and lower eyelids. Wearers of rigid lenses showed a tendency for meibomian gland dropout in the upper eyelid, whereas wearers of SCLs showed a tendency for shortening of the glands in the lower eyelid. Their data suggested that lens material does not play a key role in CL-associated MGD. 

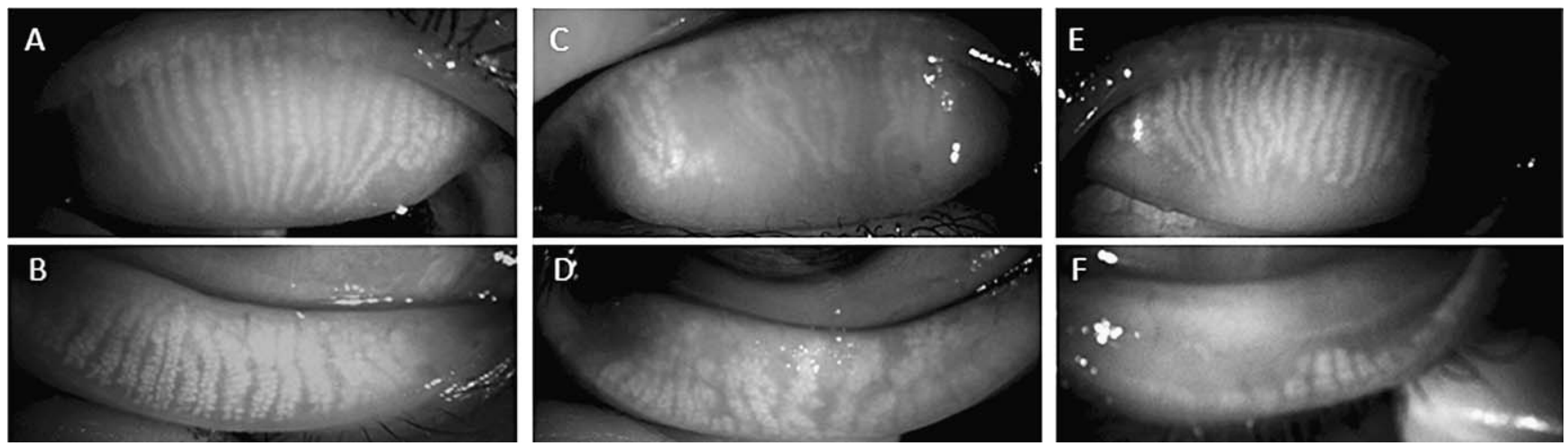

FiguRE 4. Representative noninvasive meibography images in a control subject $(\mathbf{A}, \mathbf{B})$ and in two CL wearers $(\mathbf{C}-\mathbf{F})$. Noninvasive meibography views of the meibomian glands from the conjunctival side, with the lids everted. The meibomian glands appear white. (A, B) A 31-year-old female, non-CL user. Meibomian glands in the upper (A) and lower (B) eye lids were observed. Shortening or dropout of meibomian glands was not observed. (C, D) A 37-year-old male who had used rigid CLs for 17 years. Those regions of the upper lid where meibomian glands were absent, appear black (drop out) (C). Shortening and distortion of meibomian glands were observed in the lower eye lid (D). (E, F) In a 32-year-old female who had used hydrogel CLs for 13 years, most meibomian glands in both the upper and lower eyelids were shortened. The shortening of the meibomian glands began not at the free border of the lid (in the region of the orifices), but proximally (in the fixed border of the tarsal plate).

\section{Acinar Density and Size}

Villani and colleagues ${ }^{332}$ examined morphological changes in meibomian glands and the status of periglandular inflammation in CL wearers by LSCM (Fig. 5) and then investigated the relation between clinical and confocal findings. LSCM was applied to determine the cell density of the mucocutaneous junction epithelium, acinar unit density and diameter, glandular orifice diameter, meibum secretion reflectivity, and the appearance of the glandular interstice and acinar wall. The duration of CL wear was found to be correlated with acinar unit diameter $(P<0.05)$. Morphological changes in the meibomian glands revealed by LSCM were indicative of signs of meibomian gland dropout, duct obstruction, and periglandular inflammation. A comprehensive LSCM evaluation of the ocular surface in CL wearers should better clarify the role of meibomian gland dropout and eyelid margin inflammation in the pathogenesis of CL-induced dry eye.

\section{Meibum Composition}

It remains unclear whether CL wear affects meibum composition or whether meibum composition affects the comfort of CL wear. Robin and colleagues ${ }^{333}$ found that all 15 subjects who wore EW SCLs and had lipid deposition on the lens showed abnormalities of meibomian gland morphology. Only 2 of the 13 subjects without lipid deposition on the lens had meibomian gland abnormalities. These results suggest that MGD may be associated with the development of SCL deposits, which can impact lens wettability and ultimately lead to CLD.

It is possible that CL wear affects not only the lipid layer of the tear film but also meibum composition itself. However, there is still a dearth of information regarding the exact nature of
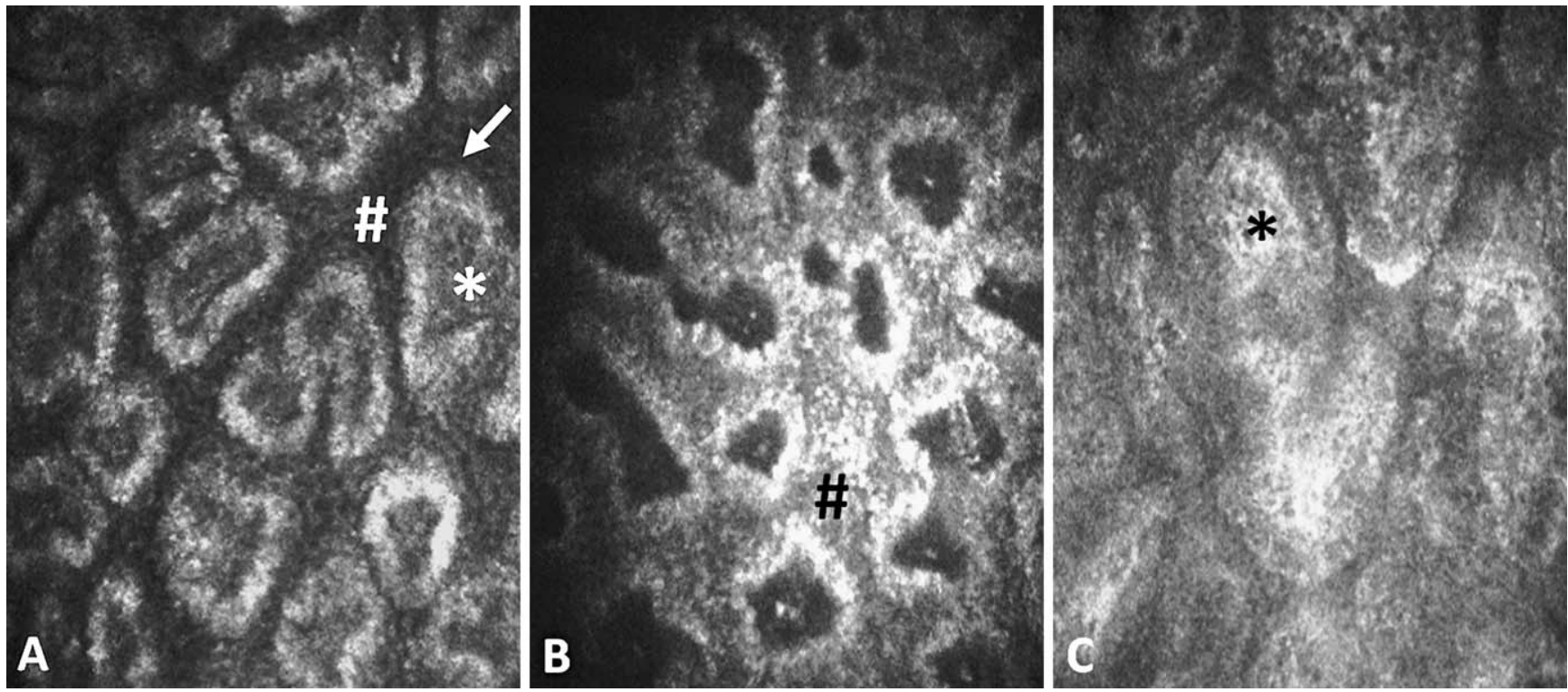

Figure 5. Meibomian gland changes in CL wearers, illustrated by in vivo confocal microscopy, performed at the lid margin. (A) Meibomian glands of a 35-year-old male, showing no obvious changes in acinar lumina (*), wall thickness (arrow), or interstitial space (\#). (B) A 32-year-old male: The acinar unit density and size are slightly reduced and there is apparent periglandular infiltration (\#), presumably by inflammatory cells. (C) A 39-yearold female: The acinar units appear greatly enlarged and hyper-reflective $(*)$ 


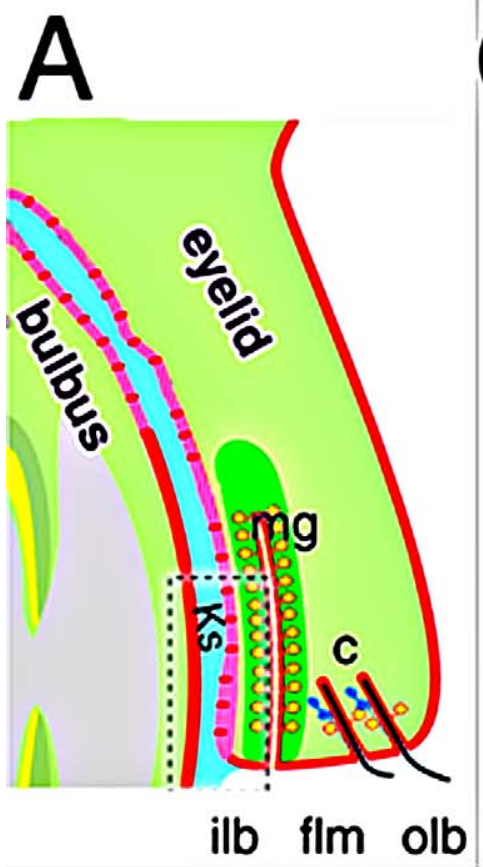

B

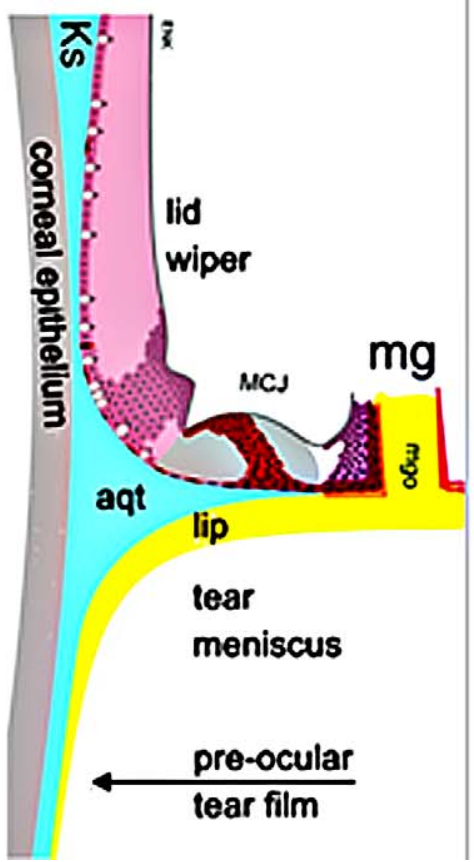

INNER Lid

BOR-

DER

(ilb)

C

$\mathrm{O}$

N

J

U

N

C

T

I

V

A

L

M

U

C

O

$\mathrm{S}$

A
L I D M A R G I N

(fim)

FREE LIO MARGIN $\because$ Muca-Cutaenous Junction Epidermis (Skin)

Figure 6. Tissue zones at the posterior eye lid margin. (A) Complete upper eye lid with meibomian gland (mg) and cilia (c); the area marked by a dotted rectangle represents the inner lid border. The rounded outer lid border (olb) can be differentiated from the sharp inner one (ilb) and the free lid margin (flm) extends from the cilia (c) to the meibom orifice. (B) The inner lid border is seen with the aqueous tear meniscus (aqt) overlying the line of Marx, and the tear film lipid layer (lip, not to size). The lid wiper is the only point of the lid margin that is apposed to and in touch with the globe; the upper tarsal conjunctiva is separated from the globe by Kessing's space (Ks in $[\mathbf{A}, \mathbf{B}]$ ). The marginal conjunctiva constitutes a thickened epithelial lip that represents the device for distribution of the tear film during a blink. (C) The lid wiper has goblet cells (white dots in [B, C]) for a rich mucin-water gel at the surface for lubrication and reduction of friction. Further zones of the posterior lid border are the mucocutaneous junction (mcj, the surface of which is the line of Marx) located between the crest of the inner lid border and the meibom orifice. The cornified epidermis extends from the free lid margin around the posterior rim of the meibom orifices where the meibomian oil is delivered onto the precorneal tearfilm. In most parts only the surface cells are shown. (A) Reprinted with permission from Knop N, Korb DR, Blackie CA, Knop E. The lid wiper contains goblet cells and goblet cell crypts for ocular surface lubrication during the blink. Cornea. 2012;31:668-679. (B, C) Modified from Knop E, Knop N, Zhivov A, et al. The lid wiper and mucocutaneous junction anatomy of the human eyelid margins: an in vivo confocal and histological study. J Anat. 2011;218:449-461. 


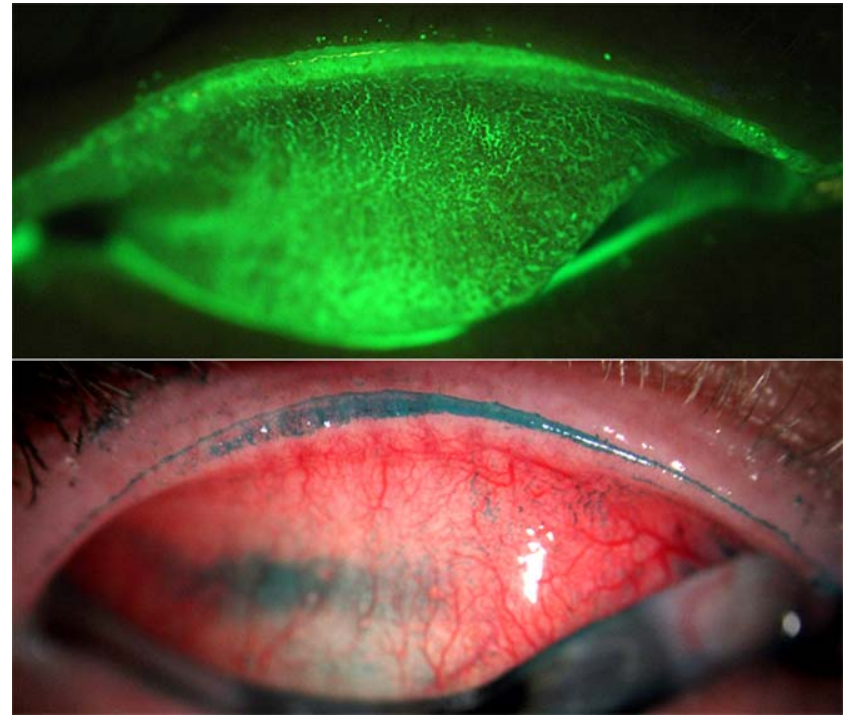

Figure 7. Lid wiper epitheliopathy. Horizontal band of lid margin staining extending horizontally from the medial canthus to the lateral canthus, and from the Marx line (sharp green line or border of superior staining) to the tarsal sulcus fold. Lid wiper epitheliopathy stained with fluorescein (top) and lissamine green (bottom). Photo courtesy of Sruthi Srinivasan.

meibum, as a result of the small sample quantities available. Recent advances in analytical techniques have provided some insight into meibum composition, ${ }^{334,335}$ but further work is necessary to determine the extent of interindividual variability in normal meibum, its effect on the comfort of CL wear, and the effect of lens wear on meibum composition.

\section{ImpaCt OF CLS ON THE LID MARgins}

\section{Lid Margin Anatomy}

The lid margin can be structurally and functionally differentiated into three distinct zones: the anterior and posterior lid border, and the free lid margin that is located between these. ${ }^{2}$ The posterior border has at least three zones (Fig. 6) ${ }^{336}$ : the posterior extension of the free lid margin skin epidermis (that encircles the meibomian orifices), the transition between the epidermis and conjunctival mucosa (mucocutaneous junction with its surface being the line of Marx), and the lid wiper zone (or the marginal conjunctiva).

The lid-wiper region is a thickened epithelial "lip" that has a conjunctival mucosal morphology that extends from the tarsal conjunctiva up to the crest of the posterior lid border, is apposed to the globe, and helps to distribute the precorneal tear film. The lid wiper contains goblet cells that produce mucin, which is likely used for lubrication and reduces the frictional force between the globe and lid margin during blinking. ${ }^{296}$ The lid wiper, because it is conceivably the only part of the lid margin that is in direct contact with the globe, ${ }^{337}$ will be in contact with the CL surface and is thus subjected to mechanical friction during the blink. The lid wiper zone has the highest neural sensitivity of all the conjunctival and lid regions, and is similar in this respect to the central cornea. ${ }^{39,338}$ Thus, it is of obvious importance during lens wear.

The line of Marx extends from the crest of the posterior lid border and is seen at the bottom of the tear meniscus. ${ }^{339} \mathrm{~A}$ thin band of stainable epithelial cells directly behind the mucocutaneous junction is the basis for Marx's line. Previously, the line of Marx was assumed to be the zone in touch with the globe and to represent the wiping surface of the lid border. ${ }^{340,341}$ However, this theory is not supported by its geometrical orientation to the globe, by the fact that it is visible in the upper eye lid without lid eversion, ${ }^{342}$ and because it lacks specific lubrication. ${ }^{296}$

The conjunctiva extending proximally from the posterior lid margin to the subtarsal fold, corresponds to the lid-wiper region of the lid margin, ${ }^{343,344}$ which is directly apposed to the surface of the globe and is important in tear distribution during blinking and eye movements. ${ }^{336}$ Riolan's muscle, the most central part of the orbicularis muscle at the lid margin, probably plays a role in this, as does the lubricative function of the goblet cells present in this region. 296

\section{Lid Wiper Epitheliopathy}

A thickened epithelium at the posterior lid margin was observed as long ago as 1877 by Sattler ${ }^{345}$ and later by Virchow and Saemisch. ${ }^{346}$ However, its immediate functional implication was not recognized until the mid-1960s by Ehlers. ${ }^{347}$ He noticed that this "bead gliding over the cornea" must be assumed to be a perfect "windscreen wiper." More recently, this region has received increased attention because of an observation by Korb and colleagues ${ }^{343,344,348}$ linking changes in this region of the lid in subjects who are symptomatic of dryness. The authors postulate that when the tear film is thinned or becomes unstable, or a lens surface is not stable and wettable, there is an increased mechanical/frictional effect on the lid-wiper region, as the lid travels across the ocular or lens surface during blinking. This process may lead to lid-wiper trauma and epitheliopathy, which can be viewed clinically by staining the marginal conjunctiva with commonly used ophthalmic dyes ${ }^{343,344,349}$ (Fig. 7).

LWE is found in $67 \%$ to $80 \%$ of symptomatic CL wearers, but in only $13 \%$ to $32 \%$ of asymptomatic subjects. ${ }^{343,350}$ This condition is also observed in the lower eyelid, ${ }^{351}$ but significantly different LWE scores between symptomatic and asymptomatic subjects were found only in the upper eyelid. ${ }^{352}$ By histology it has been verified in selected cases that cells with atypical keratinization (para-keratinization) increase in number and extend from the natural stainable line of Marx, where they physiologically occur, over the surface of the lid wiper epithelium. ${ }^{336}$

LWE may be one of the few clinical signs truly associated with dryness in lens wearers and nonwearers and much work is currently under way to determine its value in providing a better understanding of CLD.

\section{Changes in Normal Microbiota}

The lid margin is more frequently colonized with microbes than the conjunctiva and CLs, ${ }^{353}$ but the frequency of isolation varies. The number of colony-forming units that can be grown from swabs of the lid range from zero in some subjects up to $465.354-357$

As shown in the Table, the most frequently isolated microbes are the coagulase-negative staphylococci, in both non-lens wear $^{358-361}$ and during lens wear. $353,354,356,357,360,362,363$ Other commonly isolated bacteria from both lens wearers and nonlens wearers include Micrococcus sp., viridans streptococci and other Streptococcus sp., Corynebacterium sp., Propionibacterium sp., and Bacillus sp. Gram-negative bacteria are not commonly isolated from the lid margins of CL or non-CL wearers. Stapleton and colleagues ${ }^{353}$ found that the frequency of isolation of microbes from lids increased significantly with time for experienced wearers of DW lenses, but for experienced wearers of EW lenses the frequency of isolation of microbes from lids reduced with time, but there was a greater frequency of isolation of potentially pathogenic microbes during EW. Other 
TABLE. Frequency of Microbes Isolated From Lids of Non-Lens Wearers and Lens Wearers ${ }^{353,354,356-361,363}$

\begin{tabular}{|c|c|c|}
\hline Microbial Type & $\begin{array}{c}\text { Non-CL Wearers, } \\
\% \text { Subjects }\end{array}$ & $\begin{array}{c}\text { CL Wearers, } \\
\% \text { Subjects }\end{array}$ \\
\hline \multicolumn{3}{|c|}{ Gram-positive bacteria: Firmicutes, Firmibacteria, Bacillales } \\
\hline Coagulase-negative staphylococci & $84-100$ & $28-97$ \\
\hline capitis/warneri/cobnii/saprophyticus & $<1$ & $2-43$ \\
\hline epidermidis/bominis & 28 & $25-62$ \\
\hline baemolyticus & & $2-8$ \\
\hline lugdunensis & & $<1-3$ \\
\hline byicus & & 5 \\
\hline intermedius & & $<1-2$ \\
\hline schleiferi & $<1$ & $1-3$ \\
\hline Staphylococcus aureus & 3 & $<1-21$ \\
\hline Planococcus sp. & & $<1-1$ \\
\hline Bacillus sp. & $22-26$ & $<1-5$ \\
\hline \multicolumn{3}{|c|}{ Gram-positive bacteria: Firmicutes, Firmibacteria, Lactobacillales } \\
\hline Streptococcus pneumoniae & & $<1$ \\
\hline S. pneumoniae and viridans streptococci & 6 & $<1-3$ \\
\hline Viridans streptococci & $<1-41$ & $1-15$ \\
\hline Streptococcus sp. & 4 & $1-6$ \\
\hline Lactobacillus sp. & & $<1-1$ \\
\hline \multicolumn{3}{|c|}{ Gram-positive bacteria: Actinobacteria, Actintobacteridae, Actinomycetales } \\
\hline Micrococcus sp. & $6-14$ & $0-26$ \\
\hline Stomatococcus sp. & & $1-2$ \\
\hline Corynebacterium sp. & 43 & $<1-32$ \\
\hline Propionibacterium sp. & $4-18$ & $<1-61$ \\
\hline \multicolumn{3}{|c|}{ Gram-negative bacteria: Proteobacteria, Gamma proteobacteria, Pseudomonadales } \\
\hline Acinetobacter baumannii & 4 & \\
\hline Acinetobacter sp. & $<1$ & $<1-9$ \\
\hline Moraxella sp. & $<1$ & $1-3$ \\
\hline Moraxella catarrbalis & & $<1$ \\
\hline Neisseria $\mathrm{sp}$. & $5-6$ & $<1-6$ \\
\hline Pseudomonas sp. & $<1$ & $1-3$ \\
\hline Pseudomonas aeruginosa & & $<1-1$ \\
\hline \multicolumn{3}{|c|}{ Gram-negative bacteria: Proteobacteria, Gamma proteobacteria, Enterobacteriales } \\
\hline Escherichia coli & $<1-3$ & \\
\hline Escherichia vulneris & $<1$ & $<1-1$ \\
\hline Enterobacter sp. & & $<1-1$ \\
\hline Enterobacter cloacae & & $<1$ \\
\hline Proteus sp. & 3 & \\
\hline Serratia marcescens & $<1-6$ & $<1-3$ \\
\hline Serratia ficaria & 6 & $<1-1$ \\
\hline Serratia liquefaciens & & 3 \\
\hline \multicolumn{3}{|c|}{ Gram-negative bacteria: Proteobacteria, Gamma proteobacteria, Pasteurellales } \\
\hline Haemophilus influenzae & $<1$ & $<1-5$ \\
\hline Haemophilus parainfluenzae & & $<1$ \\
\hline \multicolumn{3}{|c|}{ Gram-negative bacteria: Proteobacteria, Beta proteobacteria, Burkholderiales } \\
\hline Achromobacter sp. & & $<1-1$ \\
\hline Achromobacter xylosoxidans & & $<1$ \\
\hline \multicolumn{3}{|c|}{ Gram-negative bacteria: Bacteroidetes, Flavobacteriaceae, Flavobacteriales } \\
\hline Chryseobacterium meningosepticum & & $<1$ \\
\hline Unidentified gram-negative rods & $<1-2$ & $2-5$ \\
\hline Fungi (molds or yeasts) & & $2-4$ \\
\hline
\end{tabular}

microbes, such as fungi or protozoa, are not usually isolated. There are no reports of viral colonization of lids in healthy asymptomatic subjects.

There have been no studies to date examining the lid microbiota during CLD. One study ${ }^{359}$ examined the lid microbiota of dry-eye subjects (including those with MGD or
Sjögren's syndrome) and found that all dry-eye subjects had increased numbers of colonies of bacteria isolated compared with healthy non-dry eye subjects $(106 \pm 82$ vs. $12 \pm 18$ colony-forming units per lid, respectively). There also tended to be more frequent lid colonization by Corynebacterium sp., Staphylococcus aureus, and coliform bacteria in the dry-eye 
subjects compared with the non-dry eye control group. Given these findings, and the changes that occur to the lid microbiota during lens wear, there is the possibility that the ocular microbiota might have some role in CLD.

\section{IMPACT OF CLS ON BuINKING}

Blink patterns impact lens movement and the degree to which the lens and ocular surface may dry between blinks, both of which can affect the interaction of the lens with the ocular surface. In addition, a lens that is too mobile will interact with the lid during the blink and can influence lens comfort. Thus, consideration of blinking in CL wearers is warranted.

The manner in which a CL interacts with the ocular surface during eye movement and blinking is distinctly different for soft, rigid, or scleral lenses, due to differences in size, material, modulus, form, and fitting philosophy for these lens types. Rigid corneal lenses require a greater period of adaptation and often modify blink patterns during this adaptation phase. Although soft lenses are intrinsically tolerable, ${ }^{364}$ acceptance is greatly influenced by a variety of material properties, including water content, modulus, oxygen transmission, and wettability. Lens surface drying and feelings of discomfort will potentially impact blink frequency.

\section{Blinking and Its Role in CLD}

Blink rate is strongly influenced by the surrounding environment, attention, eye exposure, personal activity, and mental state and may vary with age and sex. Wide variations in normal blink rate are reported, likely due to the influence of different environmental conditions or measurement techniques. Blink rate is increased in dry eye disease and is further amplified by increasing airflow over the eye, in both healthy individuals and subjects with dry eye complaints. ${ }^{365,366}$ The increased blink rate appears to serve two functions, in that it refreshes the tear film more frequently and also increases the period of tear film coverage over the ocular surface, as both blink frequency and blink time are increased. In contrast, a reduction in blink rate increases the blink interval, thereby increasing evaporative loss from the eye for a given palpebral aperture size. This has obvious consequences for lens behavior, particularly related to tear film break-up and surface drying over the lens. Finally, blink completeness is reduced in CL wearers compared with healthy individuals. ${ }^{46}$

\section{Movement During Blinking}

In the CL wearer, physical stresses are generated between the lens and the ocular surface, which vary according to lens type and fit, the nature and extent of the lid and eye movements, and how the lens sits on the surface of the eye.

The points of contact with the cornea and conjunctiva in the primary position of gaze differ significantly among the major lens subtypes. In the blink interval, rigid corneal lenses sit on the cornea, within the palpebral aperture, either making no contact with the lids, or, with a lid-attached fit, engaging with the upper tarsus. Occasionally, the lower lens edge may be supported on the lower lid margin. ${ }^{367}$ In comparison, soft and scleral lenses tuck beneath the upper and lower lid margins, straddling the cornea and perilimbal conjunctiva, and, with scleral lenses, extend onto the bulbar conjunctiva. Although soft lenses are flexible and modify their shape over the corneal and limbal area, scleral lenses are not, and conform very differently to either rigid corneal or soft lenses. There is only a very thin film of fluid between a soft lens and the cornea and minimal tear exchange occurs. The tear film is more substantial in the case of corneal and scleral lenses, resulting in greater mobility for rigid corneal lenses. For the scleral lens, mobility and tear exchange is restricted by size and peripheral interactions with the bulbar conjunctiva. A key function of the blink is to replenish the tear film in front of and behind the lens. In some circumstances, lens fit may interfere with spreading of the tear film and this, along with the presence of the lens-edge-related meniscus, may encourage drying outside the edge of the lens (resulting in 3 and 9 o'clock staining), which can influence rigid lens comfort. ${ }^{368,369}$

Blinking exerts both a backward, squeeze pressure on the lens and a shearing force, parallel to its anterior surface. ${ }^{370-372}$ As the lens moves or fluid is exchanged behind the lens, these forces are transmitted to the cornea, limbus, and bulbar conjunctiva to varying degrees, according to lens type and fitting characteristics. Although there is limited tear exchange under a soft lens during the blink, the volume and distribution of fluid behind the lens is a major determinant of mobility. ${ }^{121,373}$ The post-lens tear fluid provides lubrication between the lens and the corneal surface and cushions the effects of blinking. It also facilitates tear exchange with the body of the tears and, thus, is important for the removal of cells and debris from behind the lens. ${ }^{374}$ For the relatively mobile, rigid corneal lens, the relationship between the lens and the ocular surface is dynamic. The lens moves with the eye during a large eye movement. By contrast, eye movement when wearing a wellfitted, relatively immobile soft lens will draw the lens surface across the upper and lower tarsal conjunctiva during horizontal versions, the locus of contact changing when the eye is elevated or depressed. These differences in physical interaction between lens subtypes and the ocular surface are relevant to the development of a variety of well-described complications that can result in CLD, including lid-wiper epitheliopathy. ${ }^{343}$ However, detailed studies of the relationship between the blink during wear of different CL types and CLD have yet to be undertaken.

\section{Conclusions and Future Directions}

This report has reviewed CL-associated changes to the ocular surface and adnexa, and has considered which of these changes are associated with CLD. We have concentrated on physiological changes that may be associated with CL wear, but not necessarily identified or designated as an adverse response.

In this context, some evidence is available to suggest a link among LIPCOF, conjunctival metaplasia, GCD, MGD, and LWE with CLD, with the strongest evidence being that related to MGD and LWE. No convincing evidence of a link to CLD was unearthed with respect to any of the other forms of CLassociated tissue changes considered in this report.

When investigating the source of CLD, a full examination of all the anterior ocular structures that can be impacted by CL must be undertaken. This report draws particular attention to the importance of undertaking a careful assessment of the meibomian glands and lid margins, so as to establish the role that changes to these tissue structures may play in the cause of CLD.

Potential future areas of study could include closer inspection of the role of corneal staining in CLD, the development of more repeatable methods to ascertain GCD, and extensive work characterizing changes to the meibomian glands during CL wear and the role of LWE in CLD. Such studies would benefit from longitudinal designs that attempt to understand what pathophysiological changes occur in new wearers over time and whether changes to CL materials, design, fit, or other changes impact MGD and LWE. Studies 
should also examine whether the magnitude or timing of changes can be linked to the magnitude and timing of CLD.

\section{Acknowledgments}

Disclosure: Each workshop participant's disclosure data can be found in the Appendix of the Introduction.

\section{References}

1. Knop E, Korb DR, Blackie CA, Knop N. The lid margin is an underestimated structure for preservation of ocular surface health and development of dry eye disease. Dev Ophthalmol. 2010;45:108-122.

2. Bron A, Tripathi D, Tripathi B. Ocular appendages: eyelids, conjunctiva, and lacrimal apparatus. In: Bron A, Tripathi D, Tripathi B, eds. Wolff's Anatomy of the Eye and Orbit. London: Chapman \& Hall Medical; 1997:30-84.

3. Wolff E. Anatomy of the Eye and Orbit. London: HK Lewis; 1948.

4. Knop E, Knop N. A functional unit for ocular surface immune defense formed by the lacrimal gland, conjunctiva and lacrimal drainage system. Adv Exp Med Biol. 2002;506:835844.

5. Knop E, Knop N. Anatomy and immunology of the ocular surface. Chem Immunol Allergy. 2007;92:36-49.

6. Paulsen F. Functional anatomy and immunological interactions of ocular surface and adnexa. Dev Ophthalmol. 2008; 41:21-35.

7. Bonini S, Lambiase A, Sgrulletta R, Bonini S. Allergic chronic inflammation of the ocular surface in vernal keratoconjunctivitis. Curr Opin Allergy Clin Immunol. 2003;3:381-387.

8. Stern ME, Siemasko KF, Gao J, Calonge M, Niederkorn JY, Pflugfelder SC. Evaluation of ocular surface inflammation in the presence of dry eye and allergic conjunctival disease. Ocul Surf. 2005;3:S161-S164.

9. Tseng SC. Amniotic membrane transplantation for ocular surface reconstruction. Biosci Rep. 2001;21:481-489.

10. Kruse FE, Reinhard T. Limbus transplantation for reconstruction of the ocular surface [in German]. Ophthalmologe. 2001;98:818-831.

11. Tsai RJ, Sun TT, Tseng SC. Comparison of limbal and conjunctival autograft transplantation in corneal surface reconstruction in rabbits. Ophthalmology. 1990;97:446-455.

12. Geerling G, Borrelli M. Adnexal surgery for severe ocular surface disease. Semin Ophthalmol. 2005;20:101-112.

13. Dogru M, Tsubota K. Current concepts in ocular surface reconstruction. Semin Ophthalmol. 2005;20:75-93.

14. Fernandes M, Sridhar MS, Sangwan VS, Rao GN. Amniotic membrane transplantation for ocular surface reconstruction. Cornea. 2005;24:643-653.

15. Hopkinson A, McIntosh RS, Tighe PJ, James DK, Dua HS. Amniotic membrane for ocular surface reconstruction: donor variations and the effect of handling on TGF-beta content. Invest Ophthalmol Vis Sci. 2006;47:4316-4322.

16. Wolff E. The muco-cutaneous junction of the lid margin and the distribution of the tear fluid. Trans Ophthalmol Soc U K. 1946;66:291-308.

17. Miller KL, Polse KA, Radke CJ. Black-line formation and the "perched" human tear film. Curr Eye Res. 2002;25:155-162.

18. Gaffney EA, Tiffany JM, Yokoi N, Bron AJ. A mass and solute balance model for tear volume and osmolarity in the normal and the dry eye. Prog Retin Eye Res. 2010;29:59-78.

19. King-Smith PE, Fink BA, Hill RM, Koelling KW, Tiffany JM. The thickness of the tear film. Curr Eye Res. 2004;29:357-368.

20. Goto E, Tseng SC. Kinetic analysis of tear interference images in aqueous tear deficiency dry eye before and after punctal occlusion. Invest Ophthalmol Vis Sci. 2003;44:1897-1905.
21. Yokoi N, Yamada H, Mizukusa Y, et al. Rheology of tear film lipid layer spread in normal and aqueous tear-deficient dry eyes. Invest Ophthalmol Vis Sci. 2008;49:5319-5324.

22. Gipson IK. The ocular surface: the challenge to enable and protect vision: the Friedenwald lecture. Invest Ophthalmol Vis Sci. 2007;48:4391-4398.

23. Stern ME, Gao J, Siemasko KF, Beuerman RW, Pflugfelder SC. The role of the lacrimal functional unit in the pathophysiology of dry eye. Exp Eye Res. 2004;78:409-416.

24. Tiffany JM. Tears in health and disease. Eye (Lond). 2003;17: 923-926.

25. Sullivan DA, Wickham LA, Rocha EM, Kelleher RS, da Silveira LA, Toda I. Influence of gender, sex steroid hormones, and the hypothalamic-pituitary axis on the structure and function of the lacrimal gland. Adv Exp Med Biol. 1998;438:11-42.

26. Ruskell GL. Nerve terminals and epithelial cell variety in the human lacrimal gland. Cell Tissue Res. 1975;158:121-136.

27. Dartt DA. Signal transduction and control of lacrimal gland protein secretion: a review. Curr Eye Res. 1989;8:619-636.

28. Seifert P, Spitznas M, Koch F, Cusumano A. The architecture of human accessory lacrimal glands. Ger J Ophthalmol. 1993; 2:444-454.

29. Bron AJ, Tiffany JM. The contribution of meibomian disease to dry eye. Ocul Surf. 2004;2:149-165.

30. Gipson IK, Argueso P. Role of mucins in the function of the corneal and conjunctival epithelia. Int Rev Cytol. 2003;231: $1-49$.

31. VanderWerf F, Brassinga P, Reits D, Aramideh M, Ongerboer de Visser B. Eyelid movements: behavioral studies of blinking in humans under different stimulus conditions. J Neurophysiol. 2003;89:2784-2796.

32. Sack RA, Sathe S, Beaton A. Tear turnover and immune and inflammatory processes in the open-eye and closed-eye environments: relationship to extended wear contact lens use. Eye Contact Lens. 2003;29:S80-S82; discussion S83-S84, S192-S194.

33. Stern ME, Beuerman RW, et al. A unified theory of the role of the ocular surface in dry eye. Adv Exp Med Biol. 1998;438: 643-651.

34. Stern ME, Beuerman RW, Fox RI, Gao J, Mircheff AK, Pflugfelder SC. The pathology of dry eye: the interaction between the ocular surface and lacrimal glands. Cornea. 1998; 17:584-589.

35. Knop E, Knop N. Influence of the eye-associated lymphoid tissue (EALT) on inflammatory ocular surface disease. Ocul Surf. 2005;3:S180-S186.

36. Sullivan DA, Edwards JA, Wickham LA, et al. Identification and endocrine control of sex steroid binding sites in the lacrimal gland. Curr Eye Res. 1996;15:279-291.

37. The definition and classification of dry eye disease: report of the Definition and Classification Subcommittee of the International Dry Eye WorkShop (2007). Ocul Surf. 2007;5: 75-92.

38. Rozsa AJ, Beuerman RW. Density and organization of free nerve endings in the corneal epithelium of the rabbit. Pain. 1982;14:105-120.

39. McGowan DP, Lawrenson JG, Ruskell GL. Touch sensitivity of the eyelid margin and palpebral conjunctiva. Acta Ophthalmol (Copenh). 1994;72:57-60.

40. Paulsen F, Thale A, Schaudig U. Nasolacrimal ducts and the dry eye [in German]. Ophthalmologe. 2002;99:566-574.

41. Jordan A, Baum J. Basic tear flow. Does it exist? Ophthalmology. 1980;87:920-930.

42. Nakamori K, Odawara M, Nakajima T, Mizutani T, Tsubota K. Blinking is controlled primarily by ocular surface conditions. Am J Ophthalmol. 1997;124:24-30.

43. Naase T, Doughty MJ, Button NF. An assessment of the pattern of spontaneous eyeblink activity under the influence 
of topical ocular anaesthesia. Graefes Arch Clin Exp Ophthalmol. 2005;243:306-312.

44. Borges FP, Garcia DM, Cruz AA. Distribution of spontaneous inter-blink interval in repeated measurements with and without topical ocular anesthesia. Arq Bras Oftalmol. 2010; 73:329-332.

45. Abelson MB, Holly FJ. A tentative mechanism for inferior punctate keratopathy. Am J Ophthalmol. 1977;83:866-869.

46. Collins MJ, Iskander DR, Saunders A, Hook S, Anthony E, Gillon R. Blinking patterns and corneal staining. Eye Contact Lens. 2006;32:287-293.

47. Sullivan D. Possible mechanisms involved in the reduced tear secretion in Sjögren's syndrome. In: Homma M, Sugai S, Tojo T, Miyasaka N, Akizuki M, eds. Sjögren's Syndrome. State of the Art. Amsterdam: Kugler Press; 1994:13-19.

48. Stern ME, Pflugfelder SC. Inflammation in dry eye. Ocul Surf. 2004;2:124-130.

49. Knop E, Knop N. Lymphocyte homing in the mucosal immune system to the Eye-Associated Lymphoid Tissue (EALT). In: Zierhut M, Sullivan DA, Stern ME, eds. Immunology of the Ocular Surface and Tearfilm. Amsterdam: Swets \& Zeitlinger; 2004:35-72.

50. Pflugfelder SC, Stern ME. Future directions in therapeutic interventions for conjunctival inflammatory disorders. Curr Opin Allergy Clin Immunol. 2007;7:450-453.

51. McDermott AM, Perez V, Huang AJ, et al. Pathways of corneal and ocular surface inflammation: a perspective from the cullen symposium. Ocul Surf. 2005;3:S131-S138.

52. Dana MR, Hamrah P. Role of immunity and inflammation in corneal and ocular surface disease associated with dry eye. Adv Exp Med Biol. 2002;506:729-738.

53. Pflugfelder SC. Antiinflammatory therapy for dry eye. Am J Ophthalmol. 2004;137:337-342.

54. Pflugfelder SC. Tear fluid influence on the ocular surface. Adv Exp Med Biol. 1998;438:611-617.

55. Muller LJ, Marfurt CF, Kruse F, Tervo TM. Corneal nerves: structure, contents and function. Exp Eye Res. 2003;76:521542.

56. Marfurt CF, Cox J, Deek S, Dvorscak L. Anatomy of the human corneal innervation. Exp Eye Res. 2010;90: 478-492.

57. Cope C, Dilly PN, et al. Wettability of the corneal surface: a reappraisal. Curr Eye Res. 1986;5:777-785.

58. Argueso P, Tisdale A, Kaura R, Tiffany JM. Mucin characteristics of human corneal-limbal epithelial cells that exclude the rose bengal anionic dye. Invest Ophthalmol Vis Sci. 2006; 47:113-119.

59. Argueso P, Guzman-Aranguez A, Mantelli F, Cao Z, Ricciuto J, Panjwani N. Association of cell surface mucins with galectin3 contributes to the ocular surface epithelial barrier. J Biol Chem. 2009;284:23037-23045.

60. Miller D, Benedek G. Intraocular Light Scattering. Springfield, IL: Charles Thomas; 1973.

61. Gipson IK. Adhesive mechanisms of the corneal epithelium. Acta Ophthalmol Suppl. 1992;202:13-17.

62. Muller LJ, Pels E, Vrensen GF. The specific architecture of the anterior stroma accounts for maintenance of corneal curvature. Br J Ophthalmol. 2001;85:437-443.

63. Bron AJ. The architecture of the corneal stroma. $\mathrm{Br} J$ Ophthalmol. 2001;85:379-381.

64. Knupp C, Pinali C, Lewis PN, et al. The architecture of the cornea and structural basis of its transparency. Adv Protein Chem Struct Biol. 2009;78:25-49.

65. Watsky MA. Keratocyte gap junctional communication in normal and wounded rabbit corneas and human corneas. Invest Ophthalmol Vis Sci. 1995;36:2568-2576.

66. Spanakis SG, Petridou S, Masur SK. Functional gap junctions in corneal fibroblasts and myofibroblasts. Invest Ophthalmol Vis Sci. 1998;39:1320-1328.
67. Jester JV, Petroll WM, Cavanagh HD. Corneal stromal wound healing in refractive surgery: the role of myofibroblasts. Prog Retin Eye Res. 1999;18:311-356.

68. Gatlin J, Melkus MW, Padgett A, et al. In vivo fluorescent labeling of corneal wound healing fibroblasts. Exp Eye Res. 2003;76:361-371.

69. Dawson DG, Ubels JL, Edelhauser HF. Cornea and Sclera. In: Levin L, Nilsson SFE, Ver Hoeve J, Wu SM, eds. Adler's Physiology of the Eye. Edinburgh: Elsevier; 2011:71-130.

70. Cristol SM, Edelhauser HF, Lynn MJ. A comparison of corneal stromal edema induced from the anterior or the posterior surface. Refract Corneal Surg. 1992;8:224-229.

71. Edelhauser HF. The balance between corneal transparency and edema: the Proctor Lecture. Invest Ophthalmol Vis Sci. 2006; $47: 1754-1767$.

72. Hatton MP, Perez VL, Dohlman CH. Corneal oedema in ocular hypotony. Exp Eye Res. 2004;78:549-552.

73. Bron AJ. UV-riboflavin cross-linking of the cornea in bullous keratopathy: appraising the rationale. Cornea. 2011;30:724726; author reply 726 .

74. Bourne WM, Nelson LR, Hodge DO. Central corneal endothelial cell changes over a ten-year period. Invest Ophthalmol Vis Sci. 1997;38:779-782.

75. Lass JH, Sugar A, Benetz BA, et al. Endothelial cell density to predict endothelial graft failure after penetrating keratoplasty. Arch Ophthalmol. 2010;128:63-69.

76. Robertson DM. The effects of silicone hydrogel lens wear on the corneal epithelium and risk for microbial keratitis. Eye Contact Lens 2013;39:67-72.

77. Ladage PM. What does overnight lens wear do to the corneal epithelium? Is corneal refractive therapy different? Eye Contact Lens. 2004;30:194-197; discussion 205-206.

78. Bergmanson JP. Effects of contact lens wear on corneal ultrastructure. Cont Lens Anterior Eye. 2001;24:115-120.

79. Mathers WD, Sachdev MS, Petroll M, Lemp MA. Morphologic effects of contact lens wear on the corneal surface. CLAO J. 1992;18:49-52.

80. Tsubota K, Hata S, Toda I, Yagi Y, Sakata M, Shimazaki J. Increase in corneal epithelial cell size with extended wear soft contact lenses depends on continuous wearing time. $\mathrm{BrJ}$ Ophthalmol. 1996;80:144-147.

81. Tsubota K, Toda I, Fujishima H, Yamada M, Sugawara T, Shimazaki J. Extended wear soft contact lenses induce corneal epithelial changes. Br J Ophthalmol. 1994;78:907911.

82. Tsubota K. In vivo observation of the corneal epithelium. Scanning. 1994;16:295-299.

83. Tsubota K, Yamada M. Corneal epithelial alterations induced by disposable contact lens wear. Ophthalmology. 1992;99: 1193-1196.

84. Lemp MA, Gold JB. The effects of extended-wear hydrophilic contact lenses on the human corneal epithelium. Am J Ophthalmol. 1986;101:274-277.

85. Stapleton F, Kasses S, Bolis S, Keay L. Short term wear of high Dk soft contact lenses does not alter corneal epithelial cell size or viability. Br J Ophthalmol. 2001;85:143-146.

86. O'Leary DJ, Madgewick R, Wallace J, Ang J. Size and number of epithelial cells washed from the cornea after contact lens wear. Optom Vis Sci. 1998;75:692-696.

87. Ladage PM, Yamamoto K, Ren DH, et al. Effects of rigid and soft contact lens daily wear on corneal epithelium, tear lactate dehydrogenase, and bacterial binding to exfoliated epithelial cells. Ophthalmology. 2001;108:1279-1288.

88. Holden BA, Sweeney DF, Vannas A, Nilsson KT, Efron N. Effects of long-term extended contact lens wear on the human cornea. Invest Ophthalmol Vis Sci. 1985;26:14891501 . 
89. Patel SV, McLaren JW, Hodge DO, Bourne WM. Confocal microscopy in vivo in corneas of long-term contact lens wearers. Invest Ophthalmol Vis Sci. 2002;43:995-1003.

90. Jalbert I, Sweeney DF, Stapleton F. The effect of long-term wear of soft lenses of low and high oxygen transmissibility on the corneal epithelium. Eye (Lond). 2009;23:1282-1287.

91. Yagmur M, Okay O, Sizmaz S, Unal I, Yar K. In vivo confocal microscopy: corneal changes of hydrogel contact lens wearers. Int Ophthalmol. 2011;31:377-383.

92. Alonso-Caneiro D, Shaw AJ, Collins MJ. Using optical coherence tomography to assess corneoscleral morphology after soft contact lens wear. Optom Vis Sci. 2012;89:16191626.

93. Forte R, Cennamo G, Del Prete S, Cesarano I, Del Prete A. Scanning electron microscopy of corneal epithelium in soft contact lens wearers. Cornea. 2010;29:732-736.

94. Choo JD, Caroline PJ, Harlin DD, Papas EB, Holden BA. Morphologic changes in cat epithelium following continuous wear of orthokeratology lenses: a pilot study. Cont Lens Anterior Eye. 2008;31:29-37.

95. Cheah PS, Norhani M, Bariah MA, Myint M, Lye MS, Azian AL. Histomorphometric profile of the corneal response to shortterm reverse-geometry orthokeratology lens wear in primate corneas: a pilot study. Cornea. 2008;27:461-470.

96. Ding $\mathrm{H}, \mathrm{Pu} \mathrm{A}, \mathrm{He} \mathrm{H}$, et al. Changes in corneal biometry and the associated histology in rhesus monkeys wearing orthokeratology contact lenses. Cornea. 2012;31:926-933.

97. Nieto-Bona A, Gonzalez-Mesa A, Nieto-Bona MP, Villa-Collar C, Lorente-Velázquez A. Short-term effects of overnight orthokeratology on corneal cell morphology and corneal thickness. Cornea. 2011;30:646-654.

98. Ren DH, Yamamoto K, Ladage PM, et al. Adaptive effects of 30-night wear of hyper-O(2) transmissible contact lenses on bacterial binding and corneal epithelium: a 1-year clinical trial. Ophthalmology. 2002;109:27-39; discussion 39-40.

99. Cavanagh HD, Ladage PM, Li SL, et al. Effects of daily and overnight wear of a novel hyper oxygen-transmissible soft contact lens on bacterial binding and corneal epithelium: a 13month clinical trial. Ophthalmology. 2002;109:1957-1969.

100. Yamamoto K, Ladage PM, Ren DH, et al. Effects of low and hyper $\mathrm{Dk}$ rigid gas permeable contact lenses on $\mathrm{Bcl}-2$ expression and apoptosis in the rabbit corneal epithelium. CLAO J. 2001;27:137-143.

101. Ladage PM, Jester JV, Petroll WM, Bergmanson JP, Cavanagh HD. Role of oxygen in corneal epithelial homeostasis during extended contact lens wear. Eye Contact Lens. 2003;29:S2S6; discussion S26-S29, S192-S194.

102. Boets EP, Kerkmeer MJ, van Best JA. Contact lens care solutions and corneal epithelial barrier function: a fluorophotometric study. Ophthalmic Res. 1994;26:129-136.

103. Lin MC, Polse KA. Hypoxia, overnight wear, and tear stagnation effects on the corneal epithelium: data and proposed model. Eye Contact Lens. 2007;33:378-381; discussion 382 .

104. Lin MC, Soliman GN, Song MJ, et al. Soft contact lens extended wear affects corneal epithelial permeability: hypoxic or mechanical etiology? Cont Lens Anterior Eye. 2003;26:11-16.

105. Lin MC, Graham AD, Fusaro RE, Polse KA. Impact of rigid gaspermeable contact lens extended wear on corneal epithelial barrier function. Invest Ophthalmol Vis Sci. 2002;43:10191024.

106. Lin MC, Graham AD, Polse KA, McNamara NA, Tieu TG. The effects of one-hour wear of high-Dk soft contact lenses on corneal pH and epithelial permeability. CLAOJ. 2000;26:130133.

107. McNamara NA, Polse KA, Fukunaga SA, Maebori JS, Suzuki RM. Soft lens extended wear affects epithelial barrier function. Ophthalmology. 1998;105:2330-2335.
108. Lin $\mathrm{MC}$, Yeh TN, Graham $\mathrm{AD}$, et al. Ocular surface health during 30-day continuous wear: rigid gas-permeable versus silicone hydrogel hyper- $\mathrm{O}_{2}$ transmitted contact lenses. Invest Ophthalmol Vis Sci. 2011;52:3530-3538.

109. Duench S, Sorbara L, Keir N, Simpson T, Jones L. Impact of silicone hydrogel lenses and solutions on corneal epithelial permeability. Optom Vis Sci. 2013;90:546-556.

110. Dumbleton K. Noninflammatory silicone hydrogel contact lens complications. Eye Contact Lens. 2003;29:S186-S189; discussion S190-S191, S192-S194.

111. Markoulli M, Papas E, Cole N, Holden B. Corneal erosions in contact lens wear. Cont Lens Anterior Eye. 2012;35:2-8.

112. Lin MC, Yeh TN. Mechanical complications induced by silicone hydrogel contact lenses. Eye Contact Lens. 2013;39: 115-124.

113. Giasson C, Bonanno JA. Corneal epithelial and aqueous humor acidification during in vivo contact lens wear in rabbits. Invest Ophthalmol Vis Sci. 1994;35:851-861.

114. Holden BA. The Glenn A. Fry Award lecture 1988: the ocular response to contact lens wear. Optom Vis Sci. 1989;66:717733.

115. Morgan PB, Maldonado-Codina C. Corneal staining: do we really understand what we are seeing? Cont Lens Anterior Eye. 2009;32:48-54.

116. Guillon JP, Guillon M, Malgouyres S. Corneal desiccation staining with hydrogel lenses: tear film and contact lens factors. Ophthalmic Physiol Opt. 1990;10:343-350.

117. Norn MS. Micropunctate fluorescein vital staining of the cornea. Acta Ophthalmol (Copenh). 1970;48:108-118.

118. Brautaset RL, Nilsson $\mathrm{M}$, Leach $\mathrm{N}$, et al. Corneal and conjunctival epithelial staining in hydrogel contact lens wearers. Eye Contact Lens. 2008;34:312-316.

119. Efron N, Veys J. Defects in disposable contact lenses can compromise ocular integrity. Int Contact Lens Clin. 1992;19: 8-18.

120. Swarbrick HA, Holden BA. Rigid gas permeable lens binding: significance and contributing factors. Am J Optom Physiol Opt. 1987;64:815-823.

121. Little SA, Bruce AS. Role of the post-lens tear film in the mechanism of inferior arcuate staining with ultrathin hydrogel lenses. CLAO J. 1995;21:175-181.

122. Zadnik K, Mutti D. Inferior arcuate corneal staining in soft contact lens wearers. Int Contact Lens Clin. 1985;12:110114.

123. Barr JT. Peripheral corneal desiccation staining-lens materials and designs. Int Contact Lens Clin. 1985;12:139-142.

124. Holden B, Sweeney D, Seger RG. Epithelial erosions caused by thin high water content lenses. Clin Exp Optom. 1986;69: 103-107.

125. Orsborn GN, Zantos SG. Corneal desiccation staining with thin high water content contact lenses. CLAO J. 1988;14:8185.

126. Mirejovsky D, Patel AS, Young G. Water properties of hydrogel contact lens materials: a possible predictive model for corneal desiccation staining. Biomaterials. 1993;14: 1080-1088.

127. van der Worp E, De Brabander J, Swarbrick H, Nuijts R, Hendrikse F. Corneal desiccation in rigid contact lens wear: 3and 9-o'clock staining. Optom Vis Sci. 2003;80:280-290.

128. Ang JH, Efron N. Corneal hypoxia and hypercapnia during contact lens wear. Optom Vis Sci. 1990;67:512-521.

129. Nichols JJ, Sinnott LT. Tear film, contact lens, and patient factors associated with corneal staining. Invest Ophthalmol Vis Sci. 2011;52:1127-1137.

130. Pritchard N, Young G, Coleman S, Hunt C. Subjective and objective measures of corneal staining related to multipurpose care systems. Cont Lens Anterior Eye. 2003;26:3-9. 
131. Garofalo RJ, Dassanayake N, Carey C, Stein J, Stone R, David R. Corneal staining and subjective symptoms with multipurpose solutions as a function of time. Eye Contact Lens. 2005; 31:166-174.

132. Jones L, MacDougall N, Sorbara LG. Asymptomatic corneal staining associated with the use of balafilcon siliconehydrogel contact lenses disinfected with a polyaminopropyl biguanide-preserved care regimen. Optom Vis Sci. 2002;79: 753-761.

133. Diec J, Evans VE, Tilia D, Naduvilath T, Holden BA, Lazon de la Jara P. Comparison of ocular comfort, vision, and SICS during silicone hydrogel contact lens daily wear. Eye Contact Lens. 2012;38:2-6.

134. Willcox MD, Phillips B, Ozkan J, et al. Interactions of lens care with silicone hydrogel lenses and effect on comfort. Optom Vis Sci. 2010;87:839-846.

135. Andrasko G, Ryen K. Corneal staining and comfort observed with traditional and silicone hydrogel lenses and multipurpose solution combinations. Optometry. 2008;79:444-454.

136. Tran N, Graham AD, Lin MC. Ethnic differences in dry eye symptoms: Effects of corneal staining and length of contact lens wear. Cont Lens Anterior Eye. In press.

137. Efron N. Contact lens-induced changes in the anterior eye as observed in vivo with the confocal microscope. Prog Retin Eye Res. 2007;26:398-436.

138. Patel S, McLaren J, Hodge D, Bourne W. Normal human keratocyte density and corneal thickness measurement by using confocal microscopy in vivo. Invest Ophthalmol Vis Sci. 2001;42:333-339.

139. Hollingsworth J, Perez-Gomez I, Mutalib HA, Efron N. A population study of the normal cornea using an in vivo, slitscanning confocal microscope. Optom Vis Sci. 2001;78:706711.

140. Malik NS, Moss SJ, Ahmed N, Furth AJ, Wall RS, Meek KM. Ageing of the human corneal stroma: structural and biochemical changes. Biochim Biophys Acta. 1992;1138: 222-228.

141. Efron N, Perez-Gomez I, Morgan PB. Confocal microscopic observations of stromal keratocytes during extended contact lens wear. Clin Exp Optom. 2002;85:156-160.

142. Jalbert I, Stapleton F. Effect of lens wear on corneal stroma: preliminary findings. Aust N Z J Ophthalmol. 1999;27:211213.

143. Weed KH, MacEwen CJ, Cox A, McGhee CN. Quantitative analysis of corneal microstructure in keratoconus utilising in vivo confocal microscopy. Eye (Lond). 2007;21:614-623.

144. Hollingsworth JG, Efron N. Confocal microscopy of the corneas of long-term rigid contact lens wearers. Cont Lens Anterior Eye. 2004;27:57-64.

145. Ohta K, Shimamura I, Shiraishi A, Ohashi Y. Confocal microscopic observations of stromal keratocytes in soft and rigid contact lens wearers. Cornea. 2012;31:66-73.

146. Kallinikos P, Morgan P, Efron N. Assessment of stromal keratocytes and tear film inflammatory mediators during extended wear of contact lenses. Cornea. 2006;25:1-10.

147. Pimenides D, Steele CF, McGhee CN, Bryce IG. Deep corneal stromal opacities associated with long term contact lens wear. Br J Ophthalmol. 1996;80:21-24.

148. Brooks AM, Grant G, Westmore R, Robertson IF. Deep corneal stromal opacities with contact lenses. Aust $N Z J$ Ophthalmol 1986;14:243-249.

149. Remeijer L, van Rij G, Beekhuis WH, Polak BC, van Nes J. Deep corneal stromal opacities in long-term contact lens wear. Ophthalmology. 1990;97:281-285.

150. Pinckers A, Eggink F, Aandekerk AL, van 't Pad Bosch A. Contact lens-induced pseudo-dystrophy of the cornea? Doc Ophthalmol. 1987;65:433-437.
151. Bohnke M, Masters BR. Long-term contact lens wear induces a corneal degeneration with microdot deposits in the corneal stroma. Ophthalmology. 1997;104:1887-1896.

152. Trittibach P, Cadez R, Eschmann R, Sarra GM, Boehnke M, Frueh BE. Determination of microdot stromal degenerations within corneas of long-term contact lens wearers by confocal microscopy. Eye Contact Lens. 2004;30:127-131.

153. Hsu M, Tu E, Bouchard C. Confocal microscopy of contact lens keratitis presenting as central toxic keratopathy. Eye Contact Lens. 2011;37:377-380.

154. Holden BA, Reddy MK, Sankaridurg PR, et al. Contact lensinduced peripheral ulcers with extended wear of disposable hydrogel lenses: histopathologic observations on the nature and type of corneal infiltrate. Cornea. 1999;18:538-543.

155. Hickson S, Papas E. Prevalence of idiopathic corneal anomalies in a non contact lens-wearing population. Optom Vis Sci. 1997;74:293-297.

156. Carnt NA, Evans VE, Naduvilath TJ, et al. Contact lens-related adverse events and the silicone hydrogel lenses and daily wear care system used. Arch Ophthalmol 2009;127:16161623.

157. Chalmers RL, Keay L, McNally J, Kern J. Multicenter casecontrol study of the role of lens materials and care products on the development of corneal infiltrates. Optom Vis Sci. 2012;89:316-325.

158. Efron N. Corneal neovascularization. In: Efron N, ed. Contact Lens Complications. London: Elsevier, 2012:214-224.

159. Zantos SG, Holden BA. Transient endothelial changes soon after wearing soft contact lenses. Am J Optom Physiol Opt. 1977;54:856-858.

160. Inagaki Y, Akahori A, Sugimoto K, Kozai A, Mitsunaga S, Hamano H. Comparison of corneal endothelial bleb formation and disappearance processes between rigid gas-permeable and soft contact lenses in three classes of $\mathrm{dk} / \mathrm{l}$. Eye Contact Lens. 2003;29:234-237.

161. Vannas A, Holden BA, Makitie J. The ultrastructure of contact lens induced changes. Acta Opbthalmol (Copenb). 1984;62: 320-333.

162. Holden BA, Williams L, Zantos SG. The etiology of transient endothelial changes in the human cornea. Invest Opbthalmol Vis Sci. 1985;26:1354-1359.

163. Bonanno JA, Polse KA. Corneal acidosis during contact lens wear: effects of hypoxia and $\mathrm{CO}_{2}$. Invest Ophthalmol Vis Sci. 1987;28:1514-1520.

164. Dada VK, Jain AK, Mehta MR. Specular microscopy of unilateral hard contact lens wearers. Indian J Ophthalmol. 1989;37:17-19.

165. MacRae SM, Matsuda M, Phillips DS. The long-term effects of polymethylmethacrylate contact lens wear on the corneal endothelium. Ophthalmology. 1994;101:365-370.

166. Setala K, Vasara K, Vesti E, Ruusuvaara P. Effects of long-term contact lens wear on the corneal endothelium. Acta Ophthalmol Scand. 1998;76:299-303.

167. McMahon TT, Polse KA, McNamara N, Viana MA. Recovery from induced corneal edema and endothelial morphology after long-term PMMA contact lens wear. Optom Vis Sci. 1996;73:184-188.

168. Doughty MJ, Aakre BM, Ystenaes AE, Svarverud E. Short-term adaptation of the human corneal endothelium to continuous wear of silicone hydrogel (lotrafilcon A) contact lenses after daily hydrogel lens wear. Optom Vis Sci. 2005;82:473-480.

169. Sanchis-Gimeno JA, Lleo A, Alonso L, Rahhal MS, MartínezSoriano F. Differences in corneal anatomy in a pair of monozygotic twins due to continuous contact lens wear. Cornea. 2003;22:243-245.

170. Leem HS, Lee KJ, Shin KC. Central corneal thickness and corneal endothelial cell changes caused by contact lens use in diabetic patients. Yonsei Med J. 2011;52:322-325. 
171. Wiffen SJ, Hodge DO, Bourne WM. The effect of contact lens wear on the central and peripheral corneal endothelium. Cornea. 2000;19:47-51.

172. MacRae SM, Matsuda M, Shellans S. Corneal endothelial changes associated with contact lens wear. CLAO J. 1989;15: 82-87.

173. Stocker EG, Schoessler JP. Corneal endothelial polymegathism induced by PMMA contact lens wear. Invest Ophthalmol Vis Sci. 1985;26:857-863.

174. Schoessler JP, Woloschak MJ. Corneal endothelium in veteran PMMA contact lens wearers. Int Contact Lens Clin. 1981;8: 19-25.

175. Schoessler JP. Corneal endothelial polymegethism associated with extended wear. Int Contact Lens Clin. 1983;10:144-156.

176. Hirst LW, Auer C, Tseng SC, Khodadoust AA. Specular microscopy of hard contact lens wearers. Ophthalmology. 1984;91:1147-1153.

177. Sweeney DF. Corneal exhaustion syndrome with long-term wear of contact lenses. Optom Vis Sci. 1992;69:601-608.

178. Odenthal MT, Gan IM, Oosting J, Kijlstra A, Beekhuis WH. Long-term changes in corneal endothelial morphology after discontinuation of low gas-permeable contact lens wear. Cornea. 2005;24:32-38.

179. Esgin H, Erda N. Corneal endothelial polymegethism and pleomorphism induced by daily-wear rigid gas-permeable contact lenses. CLAO J. 2002;28:40-43.

180. Nieuwendaal CP, Odenthal MT, Kok JH, et al. Morphology and function of the corneal endothelium after long-term contact lens wear. Invest Ophthalmol Vis Sci. 1994;35:3071-3077.

181. Carlson KH, Bourne WM. Endothelial morphologic features and function after long-term extended wear of contact lenses. Arch Ophthalmol. 1988;106:1677-1679.

182. Lee JS, Park WS, Lee SH, Oum BS, Cho BM. A comparative study of corneal endothelial changes induced by different durations of soft contact lens wear. Graefes Arch Clin Exp Ophthalmol. 2001;239:1-4.

183. Suzuki N, Okamura T. The effect of disposable contact lenses on the corneal endothelium [in Japanese]. Nibon Ganka Gakkai Zasshi. 2006;110:511-519.

184. Chang SW, Hu FR, Lin LL. Effects of contact lenses on corneal endothelium - a morphological and functional study. $O p b$ thalmologica. 2001;215:197-203.

185. Doughty MJ, Aakre BM. Central versus paracentral endothelial cell density values in relation to duration of soft contact lens wear. Eye Contact Lens. 2007;33:180-184.

186. Aakre BM, Ystenaes AE, Doughty MJ, Austrheim $\varnothing$, Westerfjell B, Lie MT. A 6-month follow-up of successful refits from daily disposable soft contact lenses to continuous wear of high-Dk silicone-hydrogel lenses. Ophthalmic Physiol Opt. 2004;24:130-141.

187. Schoessler JP, Barr JT, Fresen DR. Corneal endothelial observations of silicone elastomer contact lens wearers. Int Contact Lens Clin. 1984;11:337-341.

188. Bergmanson JP. Histopathological analysis of corneal endothelial polymegethism. Cornea. 1992;11:133-142.

189. Dutt RM, Stocker EG, Wolff CH, Glavan I, Lass JH. A morphologic and fluorophotometric analysis of the corneal endothelium in long-term extended wear soft contact lens wearers. CLAO J. 1989;15:121-123.

190. Bourne WM. Clinical estimation of corneal endothelial pump function. Trans Am Ophthalmol Soc. 1998;96:229-239; discussion 239-242.

191. Oyster CW. The cornea and the sclera. In: Oyster CW, ed. The Human Eye: Structure and Function. Sunderland, MA: Sinauer Associates Inc; 1999:325-378.

192. Feng Y, Simpson TL. Comparison of human central cornea and limbus in vivo using optical coherence tomography. Optom Vis Sci. 2005;82:416-419.
193. Feng Y, Simpson TL. Corneal, limbal, and conjunctival epithelial thickness from optical coherence tomography. Optom Vis Sci. 2008;85:E880-E883.

194. Miri A, Alomar T, Nubile $M$, et al. In vivo confocal microscopic findings in patients with limbal stem cell deficiency. Br J Ophthalmol. 2012;96:523-529.

195. Goldberg MF, Bron AJ. Limbal palisades of Vogt. Trans Am Ophthalmol Soc. 1982;80:155-171.

196. Meyer PA, Watson PG. Low dose fluorescein angiography of the conjunctiva and episclera. Br J Ophthalmol. 1987;71:210.

197. Meyer PA. The circulation of the human limbus. Eye (Lond). 1989;3:121-127.

198. Schlotzer-Schrehardt U, Kruse FE. Identification and characterization of limbal stem cells. Exp Eye Res. 2005;81:247264.

199. Kulkarni BB, Tighe PJ, Mohammed I, et al. Comparative transcriptional profiling of the limbal epithelial crypt demonstrates its putative stem cell niche characteristics. BMC Genomics. 2010;11:526.

200. Tseng SC. Concept and application of limbal stem cells. Eye (Lond). 1989;3:141-157.

201. McMonnies CW, Chapman-Davies A, Holden BA. The vascular response to contact lens wear. Am J Optom Physiol Opt. 1982;59:795-799.

202. Papas EB. The role of hypoxia in the limbal vascular response to soft contact lens wear. Eye Contact Lens. 2003;29:572S74; discussion S83-S84, S192-S194.

203. Dumbleton KA, Chalmers RL, Richter DB, Fonn D. Vascular response to extended wear of hydrogel lenses with high and low oxygen permeability. Optom Vis Sci. 2001;78:147-151.

204. Papas EB, Vajdic CM, Austen R, Holden BA. High-oxygentransmissibility soft contact lenses do not induce limbal hyperaemia. Curr Eye Res. 1997;16:942-948.

205. Diec J, Lazon de la Jara P, Willcox M, Holden BA. The clinical performance of lenses disposed of daily can vary considerably. Eye Contact Lens. 2012;38:313-318.

206. Long B, McNally J. The clinical performance of a silicone hydrogel lens for daily wear in an Asian population. Eye Contact Lens. 2006;32:65-71.

207. Malet F, Pagot R, Peyre C, et al. Clinical results comparing high-oxygen and low-oxygen permeable soft contact lenses in France. Eye Contact Lens. 2003;29:50-54.

208. Chalmers RL, Dillehay S, Long B, et al. Impact of previous extended and daily wear schedules on signs and symptoms with high Dk lotrafilcon A lenses. Optom Vis Sci. 2005;82: 549-554.

209. Long B, Schweizer H, Bleshoy H, Zeri F. Expanding your use of silicone hydrogel contact lenses: using lotrafilcon A for daily wear. Eye Contact Lens. 2009;35:59-64.

210. Woods J, Jones L, Woods C, Schneider S, Fonn D. Use of a photographic manipulation tool to assess corneal vascular response. Optom Vis Sci. 2012;89:215-220.

211. Dillehay SM, Miller MB. Performance of Lotrafilcon B silicone hydrogel contact lenses in experienced low-Dk/t daily lens wearers. Eye Contact Lens. 2007;33:272-277.

212. Bergenske P, Long B, Dillehay S, et al. Long-term clinical results: 3 years of up to 30-night continuous wear of lotrafilcon A silicone hydrogel and daily wear of low-Dk/t hydrogel lenses. Eye Contact Lens. 2007;33:74-80.

213. Stern J, Wong R, Naduvilath TJ, Stretton S, Holden BA, Sweeney DF. Comparison of the performance of 6- or 30night extended wear schedules with silicone hydrogel lenses over 3 years. Optom Vis Sci. 2004;81:398-406.

214. Fahmy M, Long B, Giles T, Wang CH. Comfort-enhanced daily disposable contact lens reduces symptoms among weekly/ monthly wear patients. Eye Contact Lens. 2010;36:215-219. 
215. Santodomingo-Rubido J. The comparative clinical performance of a new polyhexamethylene biguanide- vs a polyquad-based contact lens care regime with two silicone hydrogel contact lenses. Ophthalmic Physiol Opt. 2007;27: 168-173.

216. Jeng BH, Halfpenny CP, Meisler DM, Stock EL. Management of focal limbal stem cell deficiency associated with soft contact lens wear. Cornea. 2011;30:18-23.

217. Puangsricharern V, Tseng SC. Cytologic evidence of corneal diseases with limbal stem cell deficiency. Ophthalmology. 1995; 102:1476-1485.

218. Donisi PM, Rama P, Fasolo A, Ponzin D. Analysis of limbal stem cell deficiency by corneal impression cytology. Cornea. 2003;22:533-538.

219. Tan DT, Ficker LA, Buckley RJ. Limbal transplantation. Ophthalmology. 1996;103:29-36.

220. Jenkins C, Tuft S, Liu C, Buckley R. Limbal transplantation in the management of chronic contact-lens-associated epitheliopathy. Eye (Lond). 1993;7:629-633.

221. Martin R. Corneal conjunctivalisation in long-standing contact lens wearers. Clin Exp Optom. 2007;90:26-30.

222. Bloomfield SE, Jakobiec FA, Theodore FH. Contact lens induced keratopathy: a severe complication extending the spectrum of keratoconjunctivitis in contact lens wearers. Ophthalmology. 1984;91:290-294.

223. Clinch TE, Goins KM, Cobo LM. Treatment of contact lensrelated ocular surface disorders with autologous conjunctival transplantation. Ophthalmology. 1992;99:634-638.

224. D'Aversa G, Luchs JL, Fox MJ, Rosenbaum PS, Udell IJ. Advancing wave-like epitheliopathy. Clinical features and treatment. Ophthalmology. 1997;104:962-969.

225. Schwartz GS, Holland EJ. Iatrogenic limbal stem cell deficiency. Cornea. 1998;17:31-37.

226. Lim L, Wei RH. Laser in situ keratomileusis treatment for myopia in a patient with partial limbal stem cell deficiency. Eye Contact Lens. 2005;31:67-69.

227. Nguyen DQ, Srinivasan S, Hiscott P, Kaye SB. Thimerosalinduced limbal stem cell failure: report of a case and review of the literature. Eye Contact Lens. 2007;33:196-198.

228. Bhatia RP, Srivastava R, Ghosh A. Limbal stem cell study in contact lens wearers. Ann Ophthalmol (Skokie). 2009;41: 87-92.

229. Chan CC, Holland EJ. Severe limbal stem cell deficiency from contact lens wear: patient clinical features. Am J Ophthalmol. 2013;155:544-549.e2

230. Martin R. Corneal conjunctivalization management with high Dk RGP contact lenses. Cont Lens Anterior Eye. 2009;32: 147-150.

231. Schornack MM. Limbal stem cell disease: management with scleral lenses. Clin Exp Optom. 2011;94:592-594.

232. La Hood D, Sweeney DF, Holden BA. Overnight corneal edema with hydrogel, rigid gas-permeable and siliconeelastomer contact lenses. Int Contact Lens Clin. 1988;15: 149-153.

233. Bonanno JA. Effects of contact lens-induced hypoxia on the physiology of the corneal endothelium. Optom Vis Sci. 2001; 78:783-790.

234. Stickel TE, Bonanno JA. The relationship between corneal oxygen tension and hypoxic corneal edema. Optometry. 2002;73:598-604.

235. Klyce SD. Stromal lactate accumulation can account for corneal oedema osmotically following epithelial hypoxia in the rabbit. J Physiol. 1981;321:49-64.

236. Iskeleli G, Karakoc Y, Akdeniz-Kayhan B, Kayhan U, Gurler B, Ozkan S. Comparison of tear lactate dehydrogenase activities of different types of contact lens wearers and normal control group. CLAO J. 1999;25:101-104.
237. Thoft RA, Friend J. Biochmical aspects of contact lens wear. Am J Ophthalmol. 1975;80:139-145.

238. Martin DK, Fatt I. The presence of a contact lens induces a very small increase in the anterior corneal surface temperature. Acta Ophthalmol (Copenh). 1986;64:512-518.

239. Hill RM. Osmotic edema associated with contact lens adaptation. J Am Optom Assoc. 1975;46:897-899.

240. Efron N, Holden BA, Vannas A. Prostaglandin-inhibitor naproxen does not affect contact lens-induced changes in the human corneal endothelium. Am J Optom Physiol Opt. 1984;61:741-744.

241. Nguyen T, Soni PS, Brizendine E, Bonanno JA. Variability in hypoxia-induced corneal swelling is associated with variability in corneal metabolism and endothelial function. Eye Contact Lens. 2003;29:117-125.

242. Morgan PB, Brennan NA, Maldonado-Codina C, Quhill W, Rashid K, Efron N. Central and peripheral oxygen transmissibility thresholds to avoid corneal swelling during open eye soft contact lens wear. J Biomed Mater Res B Appl Biomater. 2010;92:361-365.

243. Holden BA, Mertz GW. Critical oxygen levels to avoid corneal edema for daily and extended wear contact lenses. Invest Ophthalmol Vis Sci. 1984;25:1161-1167.

244. Fonn D, du Toit R, Simpson TL, Vega JA, Situ P, Chalmers RL. Sympathetic swelling response of the control eye to soft lenses in the other eye. Invest Ophthalmol Vis Sci. 1999;40: 3116-3121.

245. Bergmanson JP. Histopathological analysis of the corneal epithelium after contact lens wear. J Am Optom Assoc. 1987; 58:812-818.

246. Cogan DG, Kuwabara T, Donaldson DD, Collins E. Microcystic dystrophy of the cornea. A partial explanation for its pathogenesis. Arch Ophthalmol. 1974;92:470-474.

247. Dillehay SM. Does the level of available oxygen impact comfort in contact lens wear? A review of the literature. Eye Contact Lens. 2007;33:148-155.

248. Guillon M. Are silicone hydrogel contact lenses more comfortable than hydrogel contact lenses? Eye Contact Lens. 2013;39:86-92.

249. Ruiz-Montenegro J, Mafra CH, Wilson SE, Jumper JM, Klyce SD, Mendelson EN. Gan IM, Corneal topographic alterations in normal contact lens wearers. Ophthalmology. 1993;100: 128-134.

250. Gonzalez-Meijome JM, Gonzalez-Perez J, Cerviño A, YebraPimentel E, Parafita MA. Changes in corneal structure with continuous wear of high-Dk soft contact lenses: a pilot study. Optom Vis Sci. 2003;80:440-446.

251. Liu Z, Pflugfelder SC. The effects of long-term contact lens wear on corneal thickness, curvature, and surface regularity. Ophthalmology. 2000;107:105-111.

252. Wang X, McCulley JP, Bowman RW, Cavanagh HD. Time to resolution of contact lens-induced corneal warpage prior to refractive surgery. CLAO J. 2002;28:169-171.

253. Alba-Bueno F, Beltran-Masgoret A, Sanjuan C, Biarnés M, Marín J. Corneal shape changes induced by first and second generation silicone hydrogel contact lenses in daily wear. Cont Lens Anterior Eye. 2009;32:88-92.

254. Santodomingo-Rubido J, Gilmartin B, Wolffsohn J. Refractive and biometric changes with silicone hydrogel contact lenses. Optom Vis Sci. 2005;82:481-489.

255. Yeniad B, Adam YS, Bilgin LK, Gözüm N. Effect of 30-day continuous wear of silicone hydrogel contact lenses on corneal thickness. Eye Contact Lens. 2004;30:6-9.

256. Dumbleton KA, Chalmers RL, Richter DB, Fonn D. Changes in myopic refractive error with nine months' extended wear of hydrogel lenses with high and low oxygen permeability. Optom Vis Sci. 1999;76:845-849. 
257. Maldonado-Codina C, Morgan PB, Efron N, Efron S. Comparative clinical performance of rigid versus soft hyper Dk contact lenses used for continuous wear. Optom Vis Sci. 2005;82:536-548.

258. Woods CA, Efron N. Regular replacement of daily-wear rigid gas-permeable contact lenses. J Br Contact Lens Assoc. 1996; 19:83-89.

259. Woods CA, Efron N. Regular replacement of extended wear rigid gas permeable contact lenses. CLAO J. 1996;22:172178.

260. Wilson SE, Lin DT, Klyce SD, Reidy JJ, Insler MS. Rigid contact lens decentration: a risk factor for corneal warpage. CLAO J. 1990;16:177-182.

261. Swarbrick HA, Wong G, O'Leary DJ. Corneal response to orthokeratology. Optom Vis Sci. 1998;75:791-799.

262. Alharbi A, Swarbrick HA. The effects of overnight orthokeratology lens wear on corneal thickness. Invest Ophthalmol Vis Sci. 2003;44:2518-2523.

263. Sridharan R, Swarbrick H. Corneal response to short-term orthokeratology lens wear. Optom Vis Sci. 2003;80:200-206.

264. Purslow C, Wolffsohn JS, Santodomingo-Rubido J. The effect of contact lens wear on dynamic ocular surface temperature. Cont Lens Anterior Eye. 2005;28:29-36.

265. Ooi EH, Ng EY, Purslow C, Acharya R. Variations in the corneal surface temperature with contact lens wear. Proc Inst Mech Eng H. 2007;221:337-349.

266. Maissa C, Guillon M, Garofalo RJ. Contact lens-induced circumlimbal staining in silicone hydrogel contact lenses worn on a daily wear basis. Eye Contact Lens. 2012;38:1626.

267. Maldonado-Codina C, Morgan PB, Schnider CM, Efron N. Short-term physiologic response in neophyte subjects fitted with hydrogel and silicone hydrogel contact lenses. Optom Vis Sci. 2004;81:911-921.

268. Lakkis C, Brennan NA. Bulbar conjunctival fluorescein staining in hydrogel contact lens wearers. CLAO J. 1996;22: 189-194.

269. Morgan PB, Chamberlain P, Moody K, Maldonado-Codina C. Ocular physiology and comfort in neophyte subjects fitted with daily disposable silicone hydrogel contact lenses. Cont Lens Anterior Eye. 2013;36:118-125.

270. Guillon M, Maissa C. Bulbar conjunctival staining in contact lens wearers and non lens wearers and its association with symptomatology. Cont Lens Anterior Eye. 2005;28:67-73.

271. Young G, Coleman S. Poorly fitting soft lenses affect ocular integrity. CLAO J. 2001;27:68-74.

272. Ozkan J, Ehrmann K, Meadows D, Lally J, Holden B, de la Jara PL. Lens parameter changes under in vitro and ex vivo conditions and their effect on the conjunctiva. Cont Lens Anterior Eye. 2013;36:171-175.

273. van der Worp E, de Brabander J, Hendrikse F. Evaluation of signs and symptoms in 3- and 9-o'clock staining. Optom Vis Sci. 2009;86:260-265.

274. Tighe B. Contact lens materials. In: Phillips A, Speedwell L, eds. Contact Lenses. Edinburgh: Butterworth-Heinemann; 2006:59-78.

275. Holden BA, Stephenson A, Stretton S, et al. Superior epithelial arcuate lesions with soft contact lens wear. Optom Vis Sci. 2001;78:9-12.

276. Lofstrom T, Kruse A. A conjunctival response to silicone hydrogel lens wear. Contact Lens Spectrum. 2005;20:42-44.

277. Bergmanson JP, Tukler J, Leach NE, Alabdelmoneam M, Miller WL. Morphology of contact lens-induced conjunctival epithelial flaps: a pilot study. Cont Lens Anterior Eye. 2012;35:185-188.

278. Markoulli M, Francis IC, Yong J, et al. A histopathological study of bulbar conjunctival flaps occurring in 2 contact lens wearers. Cornea. 2011;30:1037-1041.
279. Graham AD, Truong TN, Lin MC. Conjunctival epithelial flap in continuous contact lens wear. Optom Vis Sci. 2009;86: e324-e331.

280. Santodomingo-Rubido J, Wolffsohn J, Gilmartin B. Conjunctival epithelial flaps with 18 months of silicone hydrogel contact lens wear. Eye Contact Lens. 2008;34:35-38.

281. Miller WL, Narayanan S, Jackson J, Bergmanson J. The association of bulbar conjunctival folds with other clinical findings in normal and moderate dry eye subjects. Optometry 2003;74:576-582.

282. Pult H, Purslow C, Berry M, Murphy PJ. Clinical tests for successful contact lens wear: relationship and predictive potential. Optom Vis Sci. 2008;85:E924-E929.

283. Li DQ, Meller D, Liu Y, Tseng SC. Overexpression of MMP-1 and MMP-3 by cultured conjunctivochalasis fibroblasts. Invest Ophthalmol Vis Sci. 2000;41:404-410.

284. Zhang XR, Zhang ZY, Hoffman MR, Li QS, Liu B, Zhou HM. The effect of age and conjunctivochalasis on conjunctival thickness. Curr Eye Res. 2013;38:331-334.

285. Mimura T, Usui T, Yamamoto $H$. Conjunctivochalasis and contact lenses. Am J Ophthalmol. 2009;148:20-25.e1.

286. Owen CG, Fitzke FW, Woodward EG. A new computer assisted objective method for quantifying vascular changes of the bulbar conjunctivae. Ophthalmic Physiol Opt. 1996;16: 430-437.

287. Cheung AT, Hu BS, Wong SA, et al. Microvascular abnormalities in the bulbar conjunctiva of contact lens users. Clin Hemorbeol Microcirc. 2012;51:77-86.

288. Knop E, Brewitt H. Induction of conjunctival epithelial alterations by contact lens wearing. A prospective study. Ger J Ophthalmol. 1992;1:125-134.

289. Marner K. 'Snake-like' appearance of nuclear chromatin in conjunctival epithelial cells from patients with keratoconjunctivitis sicca. Acta Ophthalmol. 1980;58:849-853.

290. Knop E, Brewitt H. Conjunctival cytology in asymptomatic wearers of soft contact lenses. Graefes Arch Clin Exp Ophthalmol. 1992;230:340-347.

291. Knop E, Brewitt H. Morphology of the conjunctival epithelium in spectacle and contact lens wearers-a light and electron microscopic study. Contactologia. 1992;14E:108-120.

292. Adar S, Kanpolat A, Sürücü S, Uckakhan OO. Conjunctival impression cytology in patients wearing contact lenses. Cornea. 1997;16:289-294.

293. Sengor T, Gurdal C, Kirimlioglu H, Irkeç M, Aydin S. Colourcoded mapping technique in impression cytology-findings in soft contact lens wearers and patients with other external eye diseases. Ophthalmologica. 2002;216:155-158.

294. Simon P, Jaison S, Chopra SK, Jacob S. Conjunctival impression cytology in contact lens wearers. Indian $J$ Ophthalmol. 2002;50:301-306.

295. Guzman-Aranguez A, Argueso P. Structure and biological roles of mucin-type O-glycans at the ocular surface. Ocul Surf. 2010;8:8-17.

296. Knop N, Korb DR, Blackie CA, Knop E. The lid wiper contains goblet cells and goblet cell crypts for ocular surface lubrication during the blink. Cornea. 2012;31:668-679.

297. Schmidt TA, Sullivan DA, Knop E, et al. Transcription, translation, and function of lubricin, a boundary lubricant, at the ocular surface. JAMA Ophthalmol. 2013;131:766-776.

298. Doughty MJ. Contact lens wear and the goblet cells of the human conjunctiva-a review. Cont Lens Anterior Eye. 2011; 34:157-163.

299. Doughty MJ. Goblet cells of the normal human bulbar conjunctiva and their assessment by impression cytology sampling. Ocul Surf. 2012;10:149-169.

300. Doughty MJ. Sampling area selection for the assessment of goblet cell density from conjunctival impression cytology specimens. Eye Contact Lens. 2012;38:122-129. 
301. Doughty MJ. Contact lens wear and the development of squamous metaplasia of the surface cells of the conjunctiva. Eye Contact Lens. 2011;37:274-281.

302. Doughty MJ. Objective assessment of contact lens wearassociated conjunctival squamous metaplasia by linear measures of cell size, shape and nucleus-to-cytoplasm ratios. Curr Eye Res. 2011;36:599-606.

303. Calonge M, Diebold Y, Sáez V, et al. Impression cytology of the ocular surface: a review. Exp Eye Res. 2004;78:457472.

304. Doughty MJ. Reliability of nucleus-to-cell and nucleus-tocytoplasm calculations for conjunctival impression cytology specimens. Curr Eye Res. 2012;37:583-591.

305. Kessing SV. Investigations of the conjunctival mucin. (Quantitative studies of the goblet cells of conjunctiva). (Preliminary report). Acta Ophthalmol (Copenh). 1966;44: 439-453.

306. Efron N, Al-Dossari M, Pritchard N. Confocal microscopy of the bulbar conjunctiva in contact lens wear. Cornea. 2010; 29:43-52.

307. Allansmith MR. Pathology and treatment of giant papillary conjunctivitis. I. The US perspective. Clin Ther. 1987;9:443450 .

308. Korb DR, Allansmith MR, Greiner JV, Henriquez AS, Richmond PP, Finnemore VM. Prevalence of conjunctival changes in wearers of hard contact lenses. Am J Ophthalmol. 1980;90:336-341.

309. Spring TF. Reaction to hydrophilic lenses. Med J Aust. 1974;1: 449-450.

310. Allansmith MR, Korb DR, Greiner JV, Henriquez AS, Simon MA, Finnemore VM. Giant papillary conjunctivitis in contact lens wearers. Am J Ophthalmol. 1977;83:697-708.

311. Allansmith MR, Korb DR, Greiner JV. Giant papillary conjunctivitis induced by hard or soft contact lens wear: quantitative histology. Ophthalmology. 1978;85:766-778.

312. Allansmith MR, Baird RS, Greiner JV. Vernal conjunctivitis and contact lens-associated giant papillary conjunctivitis compared and contrasted. Am J Ophthalmol. 1979;87:544-555.

313. Lofstrom T, Anderson JS, Kruse A. Tarsal abnormalities: a new grading system. CLAO J. 1998;24:210-215.

314. Efron N, Pritchard N, Brandon K, et al. A survey of the use of grading scales for contact lens complications in optometric practice. Clin Exp Optom. 2011;94:193-199.

315. Young G, Keir N, Hunt C, Woods CA. Clinical evaluation of long-term users of two contact lens care preservative systems. Eye Contact Lens. 2009;35:50-58.

316. Knop N, Knop E. Meibomian glands. Part I: anatomy, embryology and histology of the Meibomian glands [in German]. Ophthalmologe. 2009;106:872-883.

317. Knop E, Knop N, Millar T, Obata H, Sullivan DA. The international workshop on meibomian gland dysfunction: report of the subcommittee on anatomy, physiology, and pathophysiology of the meibomian gland. Invest Ophthalmol Vis Sci. 2011;52:1938-1978.

318. Knop E, Knop N, Schirra F. Meibomian glands. Part II: physiology, characteristics, distribution and function of meibomian oil [in German]. Ophthalmologe. 2009;106: 884-892.

319. Nelson JD, Shimazaki J, Benitez-del-Castillo JM, et al. The international workshop on meibomian gland dysfunction: report of the definition and classification subcommittee. Invest Ophthalmol Vis Sci. 2011;52:1930-1937.

320. Korb DR, Henriquez AS. Meibomian gland dysfunction and contact lens intolerance. J Am Optom Assoc. 1980;51:243251.

321. Henriquez AS, Korb DR. Meibomian glands and contact lens wear. Br J Ophthalmol. 1981;65:108-111.
322. Ong BL, Larke JR. Meibomian gland dysfunction: some clinical, biochemical and physical observations. Opbthalmic Physiol Opt. 1990;10:144-148.

323. Marren SE. Contact lens wear, use of eye cosmetics, and Meibomian gland dysfunction. Optom Vis Sci. 1994;71:6062.

324. Ong BL. Relation between contact lens wear and Meibomian gland dysfunction. Optom Vis Sci. 1996;73:208-210.

325. Schaumberg DA, Nichols JJ, Papas EB, Tong L, Uchino M, Nichols KK. The international workshop on meibomian gland dysfunction: report of the subcommittee on the epidemiology of, and associated risk factors for, MGD. Invest Ophthalmol Vis Sci. 2011;52:1994-2005.

326. Arita R, Itoh K, Inoue K, Kuchiba DA, Yamaguchi T, Amano S. Contact lens wear is associated with decrease of meibomian glands. Ophthalmology. 2009;116:379-384.

327. Knop E, Knop N. Meibomian glands: part IV. Functional interactions in the pathogenesis of meibomian gland dysfunction (MGD) [in German]. Ophthalmologe. 2009; 106:980-987.

328. Blackie CA, Korb DR, Knop E, Bedi R, Knop N, Holland EJ. Nonobvious obstructive meibomian gland dysfunction. Cornea. 2010;29:1333-1345.

329. Nichols JJ, Sinnott LT. Tear film, contact lens, and patientrelated factors associated with contact lens-related dry eye. Invest Ophthalmol Vis Sci. 2006;47:1319-1328.

330. Paugh JR, Knapp LL, Martinson JR, Hom MM. Meibomian therapy in problematic contact lens wear. Optom Vis Sci. 1990;67:803-806.

331. Arita $\mathrm{R}$, Itoh $\mathrm{K}$, Inoue $\mathrm{K}$, Amano $\mathrm{S}$. Noncontact infrared meibography to document age-related changes of the meibomian glands in a normal population. Ophthalmology. 2008;115:911-915.

332. Villani E, Ceresara G, Beretta S, Magnani F, Viola F, Ratiglia R. In vivo confocal microscopy of meibomian glands in contact lens wearers. Invest Ophthalmol Vis Sci. 2011;52:52155219.

333. Robin JB, Nobe JR, Suarez E, Jester JV, Smith RE. Meibomian gland evaluation in patients with extended wear soft contact lens deposits. CLAO J. 1986;12:95-98.

334. Green-Church KB, Butovich I, Willcox M, et al. The international workshop on meibomian gland dysfunction: report of the subcommittee on tear film lipids and lipidprotein interactions in health and disease. Invest Ophthalmol Vis Sci. 2011;52:1979-1993.

335. Pucker AD, Nichols JJ. Analysis of meibum and tear lipids. Ocul Surf. 2012;10:230-250.

336. Knop E, Knop N, Zhivov A, et al. The lid wiper and mucocutaneous junction anatomy of the human eyelid margins: an in vivo confocal and histological study. J Anat. 2011;218:449461.

337. Kessing SV. A new division of the conjunctiva on the basis of x-ray examination. Acta Ophthalmol (Copenb). 1967;45: 680-683.

338. Lowther GE, Hill RM. Sensitivity threshold of the lower lid margin in the course of adaptation to contact lenses. Am J Optom Arch Am Acad Optom. 1968;45:587-594.

339. Norn MS. Vital staining of the canaliculus lacrimalis and the palpebral border (Marx' line). Acta Ophthalmol (Copenh). 1966;44:948-959.

340. Doughty MJ, Naase T, Donald C, Hamilton L, Button NF Visualisation of "Marx's line" along the marginal eyelid conjunctiva of human subjects with lissamine green dye. Ophthalmic Physiol Opt. 2004;24:1-7.

341. Shaw AJ, Collins MJ, Davis BA, Carney LG. Eyelid pressure: inferences from corneal topographic changes. Cornea. 2009; 28:181-188. 
342. Korb DR, Blackie C. Marx's line of the upper lid is visible in upgaze without lid eversion. Eye Contact Lens. 2010;36:149151.

343. Korb DR, Greiner JV, Herman JP, et al. Lid-wiper epitheliopathy and dry-eye symptoms in contact lens wearers. CLAOJ. 2002;28:211-216.

344. Korb DR, Herman JP, Greiner JV, et al. Lid wiper epitheliopathy and dry eye symptoms. Eye Contact Lens. 2005;31:2-8.

345. Sattler H. Beitrag zur Kenntnis der normalen Bindehaut des Menschen. Graefes Arch Ophthalmol. 1877;23:1-28.

346. Virchow H, Saemisch T. Mikroskopische Anatomie der üsseren Augenhaut und des Lidapparates in GraefeSaemisch Handbuch der gesamten Augenbeilkunde, Band 1, 1. Abteilung, Kapitel II. Leibzig: Verlag W. Engelmann; 1910:431.

347. Ehlers N. The precorneal film. Biomicroscopical, histological and chemical investigations. Acta Ophthalmol Suppl. 1965: 81(suppl):1-134.

348. Korb DR, Herman JP, Blackie CA, et al. Prevalence of lid wiper epitheliopathy in subjects with dry eye signs and symptoms. Cornea. 2010;29:377-383.

349. Korb DR, Herman JP, Finnemore VM, Exford JM, Blackie CA. An evaluation of the efficacy of fluorescein, rose bengal, lissamine green, and a new dye mixture for ocular surface staining. Eye Contact Lens. 2008;34:61-64.

350. Yeniad B, Beginoglu M, Bilgin LK, et al. Lid-wiper epitheliopathy in contact lens users and patients with dry eye. Eye Contact Lens. 2010;36:140-143.

351. Shiraishi A, Yamanishi S, Yamamoto Y, Yamaguchi M, Ohashi Y. Lid-wiper epitheliopathy in patients with dry eye symptoms [in Japanese]. Nihon Ganka Gakkai Zasshi. 2009;113:596-600.

352. Berry M, Pult H, Purslow C, Murphy PJ. Mucins and ocular signs in symptomatic and asymptomatic contact lens wear. Optom Vis Sci. 2008;85:E930-E938.

353. Stapleton F, Willcox MD, Fleming CM, Hickson S, Sweeney DF, Holden BA. Changes to the ocular biota with time in extended- and daily-wear disposable contact lens use. Infect Immun. 1995;63:4501-4505.

354. Stapleton F, Willcox MD, Sansey N, Holden BA. Ocular microbiota and polymorphonuclear leucocyte recruitment during overnight contact lens wear. Aust N Z J Ophthalmol. 1997;25:S33-S35.

355. Hart DE, Hosmer M, Georgescu M, Farris RL. Bacterial assay of contact lens wearers. Optom Vis Sci. 1996;73:204-207.

356. Szczotka-Flynn LB, Bajaksouzian S, Jacobs MR, Rimm A. Risk factors for contact lens bacterial contamination during continuous wear. Optom Vis Sci. 2009;86:1216-1226.

357. Ozkan J, Zhu H, Gabriel M, Holden BA, Willcox MD. Effect of prophylactic antibiotic drops on ocular microbiota and physiology during silicone hydrogel lens wear. Optom Vis Sci. 2012;89:326-335.

358. Gritz DC, Scott TJ, Sedó SF, Cevallos AV, Margolis TP, Whitcher JP. Ocular flora of patients with AIDS compared with those of HIV-negative patients. Cornea. 1997;16:400405.

359. Albietz JM, Lenton LM. Effect of antibacterial honey on the ocular flora in tear deficiency and meibomian gland disease. Cornea. 2006;25:1012-1019.

360. Sankaridurg PR, Markoulli M, de la Jara PL, et al. Lid and conjunctival micro biota during contact lens wear in children. Optom Vis Sci. 2009;86:312-317.

361. Larkin DF, Leeming JP. Quantitative alterations of the commensal eye bacteria in contact lens wear. Eye (Lond). 1991;5:70-74.

362. Willcox MD, Power KN, Stapleton F, Leitch C, Harmis N, Sweeney DF. Potential sources of bacteria that are isolated from contact lenses during wear. Optom Vis Sci. 1997;74: 1030-1038.

363. Leitch EC, Harmis NY, Corrigan KM, Wilcox MD. Identification and enumeration of staphylococci from the eye during soft contact lens wear. Optom Vis Sci. 1998;75:258-265.

364. Dumbleton KA, Woods CA, Jones LW, Fonn D. Comfort and adaptation to silicone hydrogel lenses for daily wear. Eye Contact Lens. 2008;34:215-223.

365. Tsubota K. Tear dynamics and dry eye. Prog Retin Eye Res. 1998; 17:565-596.

366. Tsubota K, Hata S, Okusawa Y, Egami F, Ohtsuki T, Nakamori $\mathrm{K}$. Quantitative videographic analysis of blinking in normal subjects and patients with dry eye. Arch Ophthalmol. 1996; 114:715-720.

367. Miller D. An analysis of the physical forces applied to a corneal contact lens. Arch Ophthalmol. 1963;70:823-829.

368. Schnider CM, Terry RL, Holden BA. Effect of lens design on peripheral corneal desiccation. J Am Optom Assoc. 1997;68: 163-170.

369. Schnider CM, Terry RL, Holden BA. Effect of patient and lens performance characteristics on peripheral corneal desiccation. J Am Optom Assoc. 1996;67:144-150.

370. Allaire PE, Flack RD. Squeeze forces in contact lenses with a steep base curve radius. Am J Optom Physiol Opt. 1980;57: 219-227.

371. Chauhan A, Radke CJ. The role of fenestrations and channels on the transverse motion of a soft contact lens. Optom Vis Sci. 2001;78:732-743.

372. Creech JL, Chauhan A, Radke CJ. Dispersive mixing in the posterior tear film under a soft contact lens. Ind Eng Chem Res. 2001;40:3015-3026.

373. Little SA, Bruce AS. Hydrogel (Acuvue) lens movement is influenced by the postlens tear film. Optom Vis Sci. 1994;71: 364-370.

374. McNamara NA, Polse KA, Brand RJ, Graham AD, Chan JS, McKenney CD. Tear mixing under a soft contact lens: effects of lens diameter. Am J Ophthalmol. 1999;127:659-665.

375. Knop E, Reale E. Fine structure and significance of snakelike chromatin in conjunctival epithelial cells. Invest Ophthalmol Vis Sci. 1994;35:711-719. 